RENATA ABRAMOVICZ FINKELSZTAIN

\title{
EFICÁCIA DA RADIOGRAFIA PANORÂMICA NA DETECÇÃO DE SINUSITES MAXILARES: ESTUDO COMPARATIVO COM TOMOGRAFIA COMPUTADORIZADA
}


Renata Abramovicz Finkelsztain

Eficácia da radiografia panorâmica na detecção de sinusites maxilares: estudo comparativo com tomografia computadorizada

Dissertação apresentada à Faculdade de Odontologia da Universidade de São Paulo, para obter o título de Mestre pelo Programa de Pós-Graduação em Odontologia.

Área de Concentração: Diagnóstico Bucal

Orientador: Prof. Dr. Israel Chilvarquer

São Paulo 
Catalogação-na-Publicação

Serviço de Documentação Odontológica

Faculdade de Odontologia da Universidade de São Paulo

Abramovicz-Finkelsztain, Renata

Eficácia da radiografia panorâmica na detecção de sinusites maxilares: estudo comparativo com tomografia computadorizada. / Renata Abramovicz- Finkelsztain; orientador: Israel Chilvarquer. -- São Paulo, 2008.

$63 p .:$ tab., fig.; $30 \mathrm{~cm}$.

Dissertação (Mestrado - Programa de Pós-Graduação em Ciências Odontológicas. Área de Concentração: Diagnóstico Bucal) -- Faculdade de Odontologia da Universidade de São Paulo.

1. Seio Maxilar 2.Tomografia computadorizada por raios $X$ 3.Radiografia panorâmica 4. Sinus da face- patologia

AUTORIZO A REPRODUÇÃO E DIVULGAÇÃO TOTAL OU PARCIAL DESTE TRABALHO, POR QUALQUER MEIO CONVENCIONAL OU ELETRÔNICO, PARA FINS DE ESTUDO E PESQUISA, DESDE QUE CITADA A FONTE E COMUNICADO AO AUTOR A REFERÊNCIA DA CITAÇÃO.

São Paulo,

Assinatura:

E-mail 


\section{FOLHA DE APROVAÇÃO}

Abramovicz- Finkelsztain, R. Eficácia da radiografia panorâmica na detecção de sinusites maxilares: estudo comparativo com tomografia computadorizada

[Dissertação de Mestrado]. São Paulo: Faculdade de Odontologia da USP; 2008

São Paulo, de de 2008

\section{Banca Examinadora}

1) $\operatorname{Prof}(a) \cdot \operatorname{Dr}(a)$.

Titulação:

Julgamento:

Assinatura:

2) $\operatorname{Prof}(a) \cdot \operatorname{Dr}(a)$.

Titulação:

Julgamento:

Assinatura:

3) $\operatorname{Prof}(a)$. $\operatorname{Dr}(a)$.

Titulação:

Julgamento:

Assinatura: 


\section{DEDICATÓRIA}

Ao meu marido Gilson, meu melhor amigo e companheiro, pelo apoio sem falhas e o carinho incondicional; pela perseverança nas suas atitudes, buscando sempre uma meta, não medindo esforços mesmo quando todos os obstáculos pareciam intransponíveis, e sem o qual este projeto não teria simplesmente sido possível.

Aos meus pais Raquel e José que me ensinaram valores muito importantes como o respeito, carinho, lealdade e perseverança. Agradeço pelo modelo de infinito amor e dedicação às filhas que tornaram possível meu sucesso.

Às minhas irmãs Suzana, Tatiana e Paula, que cada qual a sua maneira e jeito especial de ser contribuíram muito para o meu crescimento. 


\section{AGRADECIMENTOS}

Ao Prof. Dr. Israel Chilvarquer, orientador desta tese, pela sua grande dedicação e disposição no ensinar que transcendem os limites deste trabalho estendendo-se ao despertar do meu gosto pela atividade científica.

Aos professores da Disciplina de Radiologia do Departamento de Estomatologia, pelos ensinamentos transmitidos.

Aos colegas: Dr. Jorge Elie Hayek, Dr. Michel Lipiec Ximenez e Dr. Tiago Zanet, pela participação valiosa na realização deste trabalho.

À Maria Cecília Forte Muniz pela presteza e dedicação dispensadas a minha pessoa.

À amiga Claudia Galindo Novoa Barsottini pela amizade, pelos conselhos e pelo auxílio na elaboração da análise estatística.

Ao meu querido esposo Gilson, sem o qual as minhas planilhas e estatística jamais estariam no papel. 
"A mente que se abre a uma idéia jamais voltará a seu tamanho original."

Albert Einstein

"Mestre não é quem sempre ensina, mas quem de repente aprende."

João Guimarães Rosa

"Aquilo que separa aqueles que alcançam seus objetivos daqueles que não alcançam está na proporção direta daquele que possui habilidade para pedir ajuda."

Donald Keouch 
Abramovicz- Finkelsztain, R. Eficácia da radiografia panorâmica na detecção de sinusites maxilares: estudo comparativo com tomografia computadorizada [Dissertação de Mestrado]. São Paulo: Faculdade de Odontologia da USP; 2008.

\section{RESUMO}

O aumento da freqüência de cirurgias de sinus lift para reabilitação com implantes proporcionou uma maior preocupação com a fisiologia do seio maxilar.

O objetivo deste estudo é avaliar a eficácia da radiografia panorâmica na detecção de sinusites maxilares. Para o estudo foram utilizados exames pareados (panorâmica + Tomografia Computadorizada) de pacientes encaminhados ao centro de radiologia para planejamento imaginologico para implantes. As 100 radiografias panorâmicas foram avaliadas por três examinadores distintos quanto a quatro padrões radiográficos: (A) padrão compatível com a normalidade, (B) presença de velamento parcial ou total opacificação do seio maxilar, (C) presença de fenômeno de retenção de muco e (D) presença de comunicação buco sinusal. Os diagnósticos obtidos pelos examinadores foram comparados com os achados radiográficos das TCs (padrão ouro). Os resultados obtidos foram submetidos à análise de concordânica de Kappa. Concluímos que a sensibilidade diagnóstica deste exame é diretamente proporcional à experência do examinador. Concluímos também que a radiografia panorâmica utilizada isoladamente não oferece recursos diagnósticos suficientes para a detecção de sinusites maxilares.

Palavras-Chave: seio maxilar- tomografia computadorizada- patologias sinusaispanorâmica 
Abramovicz- Finkelsztain, R. Panoramic radiography efficacy at detecting maxillary sinusitis: comparative study with computed tomography [Dissertação de Mestrado]. São Paulo: Faculdade de Odontologia da USP; 2008.

\begin{abstract}
Due to the higher frequency of sinus lift surgeries for oral rehabilitation with implants, there is more concern to the physiology of the maxillary sinus.

The purpose of the present study is to evaluate the panoramic $x$-ray efficacy at detecting maxillary sinusitis. For this study, one hundred paired exams (panoramic $x-$ ray + Computed Tomography) from patients referred to a radiodiagnostic centre for dental implant placement planning were used. All panoramic x-rays were evaluated by three different observers and diagnosed for four radiographic findings: $(A)$ healthy sinus, $(B)$ mucosal swelling or total opacification of the maxillary sinus, $(C)$ presence of mucosal cysts and (D) presence of buco antral communication. The diagnoses obtained by the three observers were compared to the CT findings (gold standard). We the used Kappa analysis to determine the agreement between the observers and the gold standard. We concluded that the more experience the observer has, the higher his agreement with the CT is. We also concluded that used by itself, the panoramic $x$-ray does not provide enough resources to detect maxillary sinusitis.
\end{abstract}

Keywords: maxillary sinus, computed tomography, maxillary sinus disease, panoramic radiography 


\section{LISTA DE TABELAS}

Tabela 5.1- Acertos Puros .32

Tabela 5.2- Coeficientes de concordância do acerto completo para o examinador 1 35

Tabela 5.3- Coeficientes de concordância do acerto completo para o examinador 2

Tabela 5.4- Coeficientes de concordância do acerto completo para o examinador 3

Tabela 5.5- Coeficientes de concordância de acerto por padrão radiográfico para o examinador 1

Tabela 5.6- Coeficientes de concordância de acerto por padrão radiográfico para o examinador 2

Tabela 5.7- Coeficientes de concordância de acerto por padrão radiográfico para o examinador 3

Tabela 5.8- Coeficiente de concordância do acerto agrupado completo para o examinador 1

Tabela 5.9- Coeficiente de concordância do acerto agrupado completo para o examinador 2 .

Tabela 5.10- Coeficiente de concordância do acerto agrupado completo para o examinador 3

Tabela 5.11- Seio Maxilar D = Seio Maxilar E X Seio Maxilar D $\neq$ Seio Maxilar $E$ (acerto puro) para o examinador 1

Tabela 5.12- Seio Maxilar $D=$ Seio Maxilar $E X$ Seio Maxilar $D \neq$ Seio Maxilar $E$ (acerto puro) para o examinador 2 . 
Tabela 5.13- Seio Maxilar D = Seio Maxilar E X Seio Maxilar D\# Seio Maxilar E (acerto puro) para o examinador 3

Tabela 5.14- Seio Maxilar D = Seio Maxilar E X Seio Maxilar $D \neq$ Seio Maxilar $E$ (acerto agrupado) para o examinador 1

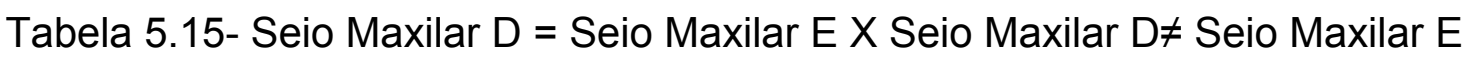
(acerto agrupado) para o examinador 2. .44

Tabela 5.16- Seio Maxilar D = Seio Maxilar E X Seio Maxilar DF Seio Maxilar E (acerto agrupado) para o examinador 3 


\section{LISTA DE ABREVIATURA E SIGLAS}

$\begin{array}{ll}\text { AAOMR } & \text { Academia Americana de Radiologia Oro- Maxilo- Facial } \\ \text { CD-ROM } & \text { Compact Disc Read Only Memory } \\ \text { DICOM } & \text { Digital Imaging and Communications in Medicine } \\ \text { DVD-ROM } & \text { Digital Video Disc Read Only Memory } \\ \text { JPEG } & \text { Joint Photographic Experts Group } \\ \text { PDF } & \text { Portable Document Format } \\ \text { TC } & \text { Tomografia Computadorizada }\end{array}$




\section{SUMÁRIO}

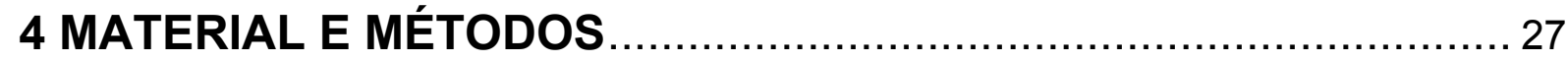

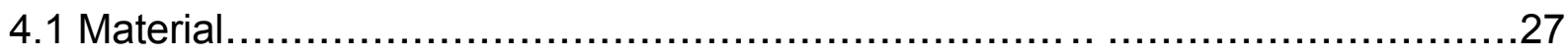

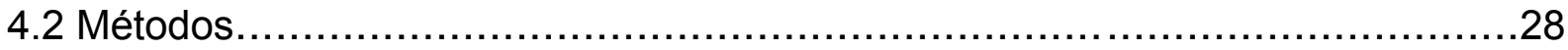

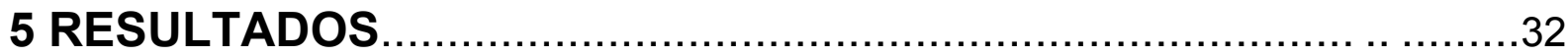

5.1 Acerto Puro

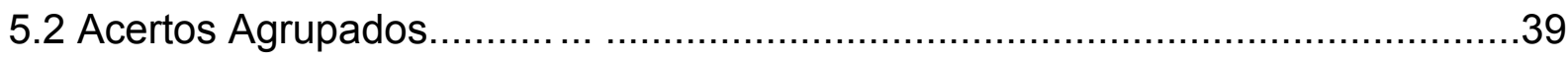

5.3 Seio Maxilar Direito $=$ Seio Maxilar Esquerdo $X$ Seio Maxilar Direito $\neq$ Seio Maxilar Esquerdo

6 DISCUSSÃO

REFERÊNCIAS. 


\section{INTRODUÇÃO}

O seio maxilar inicia seu desenvolvimento aproximadamente no terceiro mês de vida intra-uterina, no nascimento apresenta o tamanho de uma ervilha e se desenvolve e aumenta de volume até a fase adulta. É o maior dos seios paranasais que ainda incluem os seios: etmoidal, frontal e esfenoidal. Está localizado no centro da maxila e consiste basicamente em uma cavidade repleta de ar revestida por epitélio colunar ciliado pseudoestratificado. Seus limites anatômicos estão determinados pela cavidade nasal (parede medial), assoalho da órbita (parede superior) e o processo alveolar da maxila (parede inferior ou assoalho). Seu assoalho geralmente encontra-se um centímetro abaixo no nível do assoalho da cavidade nasal. O assoalho pode encontrar-se também logo acima dos ápices dos molares e pré-molares superiores podendo ainda sofrer projeções entre as raízes, restando assim apenas uma fina camada de osso cortical separando os dentes do seio maxilar. Devido à sua proximidade com a cavidade oral, o seio maxilar é de grande importância para o cirurgião-dentista; pois, sabe-se que alguns procedimentos realizados na cavidade bucal, bem como alterações patológicas que com freqüência acometem a mesma, podem exercer influência na fisiologia do seio maxilar. Como exemplo é possível citar exodontias de terceiros molares mal sucedidas ou ainda infecções periapicais no sextante posterior que podem ocasionar comunicações buco-antrais, provocando sinusopatias agudas e crônicas que podem afetar o bem-estar do paciente.

Com o desenvolvimento das técnicas cirúrgicas e de enxertia óssea na área de implantodontia, hoje é possível reabilitar com implantes, pacientes que 
antigamente eram desconsiderados por possuírem avançadas perdas ósseas, principalmente na maxila. Isso ocorria, pois; com a perda dos elementos posteriores da maxila, além da reabsorção do processo alveolar, ocorre também uma pneumatização do seio maxilar, intensificando o processo de perda de rebordo ósseo nessas regiões.

Para reabilitar esses pacientes os cirurgiões dentistas dispõem atualmente de técnicas e manobras cirúrgicas avançadas, como o procedimento de levantamento de assoalho da cavidade sinusal ("sinus lift") com a colocação de enxertos ósseos dos mais variados tipos; permitindo assim, que a reabilitação com implantes seja realizada nessas regiões.

Por esse motivo se faz necessário um estudo apurado da anatomia da região do seio maxilar, bem como das patologias que podem acometer essa estrutura anatômica a fim de se evitar complicações trans e pós-cirúrgicas.

Quando se escolhe um método diagnóstico é preciso considerar a quantidade e a validade das informações que esse método proporciona (WHITE; PHAROAH, 2004). A radiografia panorâmica é amplamente utilizada pelos cirurgiões dentistas como método de avaliação inicial e às vezes também periódica de seus pacientes, por proporcionar uma visão de todo o complexo maxilo-mandibular, de suas estruturas adjacentes e dos dentes.

Atualmente, a radiografia panorâmica também tem sido bastante indicada por cirurgiões dentistas como único método de avaliação no planejamento cirúrgico de pacientes que serão reabilitados com implantes (BEASON; BROOKS, 2001; SAKAKURA et al., 2003), apesar das suas limitações intrínsecas tais como: distorção nos sentidos vertical e mésio-distal (impossibilitando realização de mensurações adequadas), sobreposição de estruturas anatômicas circunvizinhas, 
formação de imagens fantasma que dificultam a interpretação e pela sua falta de tridimensionalidade.

A identificação adequada de reparos anatômicos importantes, bem como de alterações patológicas pré-existentes na região a ser reabilitada é de grande importância para o sucesso nas cirurgias de enxertia óssea e a reabilitação com implantes, e, portanto, o método radiográfico indicado para avaliação pré-operatória deverá fornecer todas as informações necessárias para que ocorram cirurgias bem sucedidas. 


\section{REVISÃO DE LITERATURA}

Lyon (1973) descreveu que a radiografia panorâmica é indicada para avaliação dos seios maxilares na localização de corpos estranhos, detecção de cisto e tumores e particularmente na detecção precoce de lesões malignas no interior da cavidade sinusal. Descreveu ainda que ocasionalmente a radiografia panorâmica apresenta imagem de velamento sinusal uni ou bilateral que podem ser indicativas de sinusopatias agudas ou crônicas.

Ohba (1977) e Ohba e Katayama (1976) apontaram a utilidade da radiografia panorâmica não somente para odontologia, mas também para a otorrinolaringologia. Em seus estudos, os autores compararam a eficácia da panorâmica e da técnica de Waters na detecção de lesões císticas no interior do seio maxilar, alterações escleróticas em estruturas ósseas adjacentes ao mesmo e também, na verificação de velamento e espessamento da mucosa sinusal. Os autores concluíram que as lesões do tipo císticas, bem como as lesões destrutivas do assoalho sinusal e do assoalho da cavidade nasal foram melhores definidas na radiografia panorâmica. No entanto, no que diz respeito ao velamento do seio maxilar e à esclerose de estruturas ósseas adjacentes ao mesmo, os autores verificaram que a técnica de Waters foi superior à radiografia panorâmica. Segundo os autores, a dificuldade de detecção do espessamento da mucosa sinusal, bem como das escleroses ósseas na maxila se deu devido à sobreposição da sombra da concha nasal inferior no interior do seio maxilar, dificultando a distinção entre a estrutura anatômica normal (assoalho do seio maxilar) e outras radiopacidades patológicas. Dessa forma 
concluíram que, para uma avaliação mais acurada da região do seio maxilar, as duas técnicas devem ser utilizadas simultaneamente por serem complementares.

Perez e Farman (1988) avaliaram a eficácia de técnicas radiográficas utilizadas rotineiramente na prática clínica (periapical, oclusal e panorâmica), na detecção de defeitos no seio maxilar provenientes de inflamação ou neoplasias em pacientes assintomáticos. Foi feita uma comparação da eficácia das técnicas "convencionais" (periapical, oclusal e panorâmica) com a tomografia computadorizada (TC) na detecção de defeitos radiolúcidos e radiopacos simulados em seios maxilares de crânios secos. Em todas as técnicas convencionais as radiopacidades foram mais evidentes do que as radiolucências, sendo que a radiografia panorâmica foi a mais eficiente entre as técnicas, uma vez que permitiu a visualização de defeitos radiopacos nas paredes anterior e lateral do seio maxilar e em seu assoalho. A TC, no entanto, mostrou-se superior às demais técnicas, não só por permitir uma melhor detecção tanto das radiopacidades como das radiolucências, mas; principalmente, pois essa técnica permitiu uma localização mais precisa de todos os defeitos que foram simulados.

Yoshiura et al. (1993) avaliaram as radiografias de pacientes com sinusite a fim de diferenciar os casos em que a inflamação sinusal tinha origem dental dos casos em que a origem era exclusivamente sinusal. Foram avaliados 68 pacientes com suspeita de sinusite maxilar. Os pacientes foram submetidos às radiografias convencionais (panorâmica, Waters e periapicais) que foram avaliadas para verificar a presença de doenças de origem dental: periodontite, cisto radicular e fístula bucoantral. Baseados na história clínica dos pacientes e nos achados radiográficos, os autores determinaram uma classificação das sinusites maxilares em quatro tipos: Tipo1-sinusite simples sem lesão associada; Tipo2-sinusite odontogênica na qual a 
origem dental pôde ser identificada; Tipo 3- inflamação severa do seio maxilar onde se detectava uma lesão dental, porém a sua relação com a inflamação sinusal não pôde ser estabelecida e, Tipo 4-inflamação sinusal moderada na presença de uma lesão dentária cuja contribuição para a inflamação sinusal era duvidosa. Os pacientes foram submetidos ainda também à TC, na qual se avaliou: tipo de espessamento da mucosa sinusal, presença de inflamação nos demais seios paranasais e/ou na cavidade nasal, espessamento ou esclerose da parede sinusal e a diminuição do tamanho da cavidade sinusal. Foram então comparados os achados das técnicas convencionais com a TC, considerando-se a TC como Padrão Ouro. Os autores verificaram que $77 \%$ dos casos com espessamento da mucosa infratemporal foram detectados tanto pela técnica de Waters quanto pela panorâmica, porém apenas $54 \%$ dos casos com alterações no processo zigomático foram detectados em ambas as técnicas. Quando comparadas as técnicas, os autores relataram ainda, que 17 casos que haviam sido classificados como sinusites do tipo quatro após a avaliação das imagens das técnicas convencionais foram posteriormente reclassificados como sendo 13 casos do tipo1 e quatro casos do tipo dois, após análise das imagens das TCs. Os autores concluíram que a aplicação da TC na avaliação dos diferentes tipos de sinusite é recomendada para avaliar a extensão exata da inflamação sinusal, o tipo de espessamento da mucosa (com ou sem origem odontogênica) e também a presença de espessamento do processo zigomático; uma vez que após a avaliação mais precisa oferecida pela TC, o tipo de tratamento ao qual o paciente será submetido pode ser alterado.

Ohba et al. (1994) compararam a eficácia da radiografia panorâmica e da TC na detecção de defeitos ósseos na parede posterior do seio maxilar produzidos em crânios secos. Os autores concluíram que a radiografia panorâmica isoladamente 
não é competente na avaliação de patologias sinusais, porém, devido ao elevado custo das TCs, a sua indicação deve ser criteriosamente baseada na história clínica e achados radiográficos convencionais (ainda que estes não sejam confiáveis).

Timmenga et al. (1997) verificaram na literatura que a incidência de sinusite maxilar após a realização de cirurgia para levantamento de assoalho de seio maxilar (sinus lift) poderia chegar até $20 \%$ dos casos. Apesar de esse percentual ter sido considerado pequeno pelos autores, eles afirmaram que uma vez que a ocorrência de sinusite maxilar no pós-operatório desses pacientes poderia comprometer o sucesso do enxerto sinusal, dos implantes e da saúde física do paciente; deve ser realizado um estudo minucioso pré-operatório para evitar intercorrências no pósoperatório desses pacientes. Os autores sugeriram que os pacientes devem ser avaliados clinicamente quanto a histórico de problemas sinusais e radiograficamente quanto às alterações do complexo ósteo-meatal que possam contribuir para uma drenagem deficiente do seio maxilar como, por exemplo: desvio de septo e presença de patologia na mucosa sinusal. De acordo com os autores, para obter-se um elevado índice de sucesso nas cirurgias de sinus lift é preciso tratar essas alterações, quando presentes, previamente ao procedimento cirúrgico.

Konen et al. (2000) realizaram um estudo comparando a capacidade diagnóstica para sinusite utilizando TC e a técnica de Waters. No estudo foram avaliadas radiografias de 134 pacientes com suspeita de inflamação sinusal. Todos os pacientes foram submetidos, no mesmo dia, a uma TC e a radiografia pela técnica de Waters. Foi estabelecida uma escala de classificação para os achados radiográficos: $0=$ seio normal, $1=$ espessamento da mucosa, 2=espessamento polipóide, 3=nível líquido e 4= total opacificação do seio. Foi estabelecido ainda um nível 5 que correspondia às análises inconclusivas. Em todos os exames foram 
avaliados os seios maxilares, frontal, esfenoidal e etmoidal. Nos exames tomográficos 97 pacientes $(72,4 \%)$ apresentaram alterações sinusais, sendo os seios maxilares os mais afetados- 82 pacientes com alterações uni ou bilaterais. Quando comparados com os achados das radiografias convencionais, os autores observaram que a técnica de Waters apresentou uma média de $32 \%$ de falsonegativos. Esses dados sugeriram que aproximadamente um terço das anormalidades observadas nos seios maxilares nas TC não seria observado na radiografia convencional, e que, aproximadamente um quarto dos seios avaliados como se apresentando normais pela técnica convencional, teriam sido positivamente avaliados quanto à presença de anomalias na TC. Quando foi feita a comparação das análises dos demais seios (frontal, esfenoidal e etmoidal), a concordância entre os achados foi ainda menor, demonstrando ainda mais a superioridade da TC. Os autores concluíram que somente a imagem fornecida pela técnica de Waters é insuficiente para o diagnóstico da sinusite maxilar. Além disso, alertaram também para o fato de que o uso exclusivo de técnicas convencionais para avaliar os seios paranasais não permite a exclusão de patologias importantes particularmente nos seios frontal, etmoidal e esfenoidal; e, portanto, não devem ser indicadas como único recurso de avaliação pré-tratamento.

Timmenga et al. (2002) defenderam a superioridade da TC como método diagnóstico para as alterações inflamatórias dos seios paranasais; pois, apesar de a TC ser um exame de maior custo e maior dose de radiação, é um método que permite um diagnóstico preciso das alterações inflamatórias e sua extensão, bem como a visualização adequada de reparos anatômicos importantes; evitando assim complicações cirúrgicas durante as endoscopias paranasais. 
Aalokken et al. (2003) avaliaram 47 pacientes com supeita clínica de sinusite aguda realizando radiografias pelas técnicas convencionais (Waters, Caldwell e projeções laterais) e tomografias computadorizadas. Verificaram que além de as células etmoidais não serem identificadas nas radiografias convencionais (devido à sobreposição de outras estruturas), a visualização do complexo osteomeatal (estrutura com papel importante no desenvolvimento das doenças inflamatórias do seio maxilar) também ficou comprometida. Além disso, os exames convencionais demonstraram baixa sensibilidade para avaliação de radiopacidades no seio maxilar. Os autores ainda ressaltaram que a alta dose de radiação da TC não deve ser ignorada apesar de a dose efetiva de uma TC de seios paranasais ser menor do que a contribuição anual da radiação de fundo que corresponde a aproximadamente $1 \mathrm{mSv}$.

Timmenga et al. (2003) avaliaram os efeitos do sinus lift na fisiologia do seio maxilar. Nenhum dos pacientes avaliados no estudo apresentava sinusite maxilar previamente à realização da cirurgia de sinus lift. No estudo, as reações da mucosa sinusal verificada após a cirurgia foram consideradas desprezíveis. Como os próprios autores descreveram, quando o seio maxilar é preenchido por sangue (no ato cirúrgico), acredita-se que ocorra um atraso na normalização das condições do seio maxilar devido à redução da atividade do complexo osteo-meatal, o que representa potencial risco de desenvolvimento de uma sinusite. Os resultados do estudo mostraram, no entanto, que a mucosa sinusal é capaz de se adaptar adequadamente às mudanças provocadas cirurgicamente pelo procedimento de sinus lift, principalmente se não houver comprometimento na drenagem sinusal previamente ao ato cirúrgico. Dentre as alterações que podem provocar redução da atuação do complexo osteo-meatal os autores citaram o espessamento da mucosa 
sinusal. Isso se dá, pois, se o seio maxilar encontra-se preenchido (total ou parcialmente) por hematoma e/ou seroma, o funcionamento do ostium maxilar estará comprometido, podendo ocorrer desenvolvimento de sinusite maxilar e comprometimento do sucesso do procedimento de enxerto ósseo (sinus lift).

Bouquet et al. (2004) ao avaliarem a localização de terceiros molares superiores em relação ao seio maxilar, concluíram que apesar de a radiografia panorâmica ser de grande auxílio para o cirurgião dentista no planejamento préoperatório, a mesma pode apresentar grandes deficiências devido à distorção e borramento das imagens inerentes à própria técnica. Dentre as desvantagens da técnica panorâmica os autores ainda citam: sobreposição de estruturas anatômicas, formação de imagens fantasma, ampliação vertical e mésio distal, ausência de tridimensionalidade, borramento de estruturas e avaliação inadequada/ ilusória do seio maxilar quando se compara a reduzida espessura da camada de imagem da panorâmica com a real profundidade do seio maxilar.

Beaumont et al. (2005) avaliaram a prevalência de patologias sinusais em pacientes agendados para realização de cirurgia de sinus lift. Todos os 45 pacientes foram submetidos a exames clínicos, moldagem e exames radiográficos com radiografia panorâmica. Foram feitas avaliações oclusais e sobre os modelos foram confeccionadas guias cirúrgicas para os procedimentos de sinus lift e colocação de implantes. Os pacientes fora então submetidos à TC e a um questionário clínico para determinar a existência de histórico de sinais/ sintomas de sinusite. Dos 45 pacientes, $98 \%$ (44) foram diagnosticados com periodontite e $27 \%$ (12) relataram histórico de sintomas de sinusite. Dezoito pacientes $(40 \%)$, todos diagnosticados com periodontite, também apresentaram sinais radiográficos de patologias sinusais sendo as condições mais comumente encontradas os cistos sinusais e a sinusite 
crônica (espessamento da mucosa sinusal e retenção de muco no interior do seio maxilar). Todos os pacientes diagnosticados com patologias sinusais foram tratados por um otorrinolaringologista previamente à realização do sinus lift. O estudo sugere que o sucesso da cirurgia de sinus lift em pacientes com patologias sinusais préexistentes depende do diagnóstico e tratamento apropriado dessa patologia previamente à cirurgia.

Em 2000, a Academia Americana de Radiologia Oro-Maxilo-Facial (AAOMR) publicou uma artigo editado por Tyndall e Brooks (2000), avaliando o critério de seleção de imagens para planejamento cirúrgico de colocação de implantes. A Academia considerou que o objetivo principal em se obter imagens pré-operatórias é obter informações sobre a região onde se realizará a cirurgia, principalmente em relação à: (1) quantidade de osso disponível na região bem como a orientação do rebordo alveolar; (2) situação da morfologia óssea local, incluindo rebordos em "lâmina de faca", profundidade da fossa submandibular, variações de desenvolvimento, defeitos ósseos decorrentes de extrações dentárias, integridade e espessura da cortical óssea e densidade do osso trabecular; (3) localização de reparos anatômicos que devem ser preservados durante a colocação de implantes, como: o seio maxilar, canal nasopalatino, canal alveolar inferior e o canal e forame mental; (4) presença de doença/ patologia no local de colocação do(s) implante(s). Foram avaliadas desde as técnicas radiográficas convencionais (periapicais, panorâmica e telerradiografia), até as técnicas ditas modernas (tomografia convencional e computadorizada). Até a data deste estudo, não haviam evidências publicadas que considerassem importantes para o sucesso da cirurgia de implantes a obtenção de imagens em secção transversal (uso de tomografias) dessas áreas a serem manipuladas; uma vez que o índice de sucesso vinha se mostrando alto, 
mesmo sem a utilização de imagens em múltiplos planos. No entanto, a AAOMR sugere que devido à rápida proliferação da execução das cirurgias de implantes por profissionais cada vez menos qualificados e experientes deve ocorrer uma queda nesses índices de sucesso. Dessa forma, as informações fornecidas pelas imagens em secção transversal são de grande importância para os profissionais. Além disso, a AAOMR relatou que outra preocupação em relação às cirurgias é o fato de que apesar de um elevado índice de sucesso na colocação dos implantes, os mesmo não estão sendo colocados em posições favoráveis à reabilitação protética em decorrência de um mau planejamento pré-cirúrgico. Esses motivos levaram a AAOMR a indicar a obtenção de imagens de secção transversal (tomografias) das áreas que irão ser reabilitadas cirurgicamente com implantes.

Beason e Brooks (2001) realizaram uma pesquisa na região sudeste de Michigan para verificar qual tipo de imagem para avaliação pré-cirúrgica para implantes era mais indicada pelos profissionais da região. Verificaram que a maioria das cirurgias de implantes era realizada por especialistas, e não por clínicos-gerais, que a técnica radiográfica predominantemente utilizada pelos dentistas era a radiografia panorâmica ( $80 \%$ ) e que a obtenção de imagens com tomografias era muito pouco indicada (3 a 10\% dos casos), contrariando as recomendações recentes da AAOMR.

Sakakura et al. (2003) realizaram pesquisa semelhante no Brasil e verificaram que o método diagnóstico pré-operatório solicitado com maior freqüência entre os cirurgiões dentistas é a radiografia panorâmica $(63,8 \%)$. Relataram ainda que somente $10,1 \%$ dos profissionais solicitam uma combinação de TC e radiografia panorâmica no planejamento pré-operatório para implantes. Os autores concluíram 
que o alto custo do exame tomográfico é o principal fator responsável pela sua escassa indicação no planejamento pré-cirúrgico. 


\section{PROPOSIÇÃO}

A proposta neste trabalho foi avaliar a eficiência da radiografia panorâmica na identificação de alterações patológicas no seio maxilar por meio de comparação dos achados radiográficos em arquivos digitais de radiografias panorâmicas e tomografias computadorizadas helicoidais de maxila realizadas em pacientes referidos ao centro de radiologia especializado em planejamento imaginológico para implantes. 


\section{MATERIAL E MÉTODOS}

\subsection{Material}

A amostra foi constituída por 100 exames digitalizados e arquivados de pacientes que foram encaminhados ao centro de radiologia para realização de estudo imaginológico pré-cirúrgico para colocação de implantes. Todos os pacientes foram submetidos à pelos menos dois exames radiográficos: (1) Radiografia panorâmica, realizada no aparelho OP-100 Instrumentarium; (2) Tomografia computadorizada helicoidal da maxila, realizada em um tomógrafo computadorizado helicoidal SELECT/SP (Elscint). O uso do arquivo de imagens da clínica de radiologia foi devidamente autorizado pelo responsável da mesma e pelo Comitê de ética em Pesquisa da Faculdade de Odontologia da Universidade de São Paulo (Anexo A e Anexo B).

As radiografias já se encontravam arquivadas seguindo protocolo de arquivamento da clínica que consiste em:

- (1) digitalização das radiografias panorâmicas por meio de scanner para transparências (Scanjet 4C/T, HP), com resolução de 300dpi. Utiliza-se o software Adobe Photoshop 7.0 (Adobe Systems, Inc., San Jose, Calif) para arquivar as imagens em formato JPEG, com data e registro do exame.

- (2) arquivamento em mídia DVD-ROMs das tomografias computadorizadas com a respectiva data e registro do exame. Os arquivos das tomografias são armazenados em formato DICOM (formato desenvolvido como padrão para 
armazenamento e manipulação de imagens médicas) e, portanto, necessitam de utilização de software específico para seu armazenamento. O software utilizado na clínica é o eFilm ${ }^{\text {TM }}$ (Merge Healthcare).

\subsection{Métodos}

4.2.1 Definição dos padrões radiográficos avaliados

Para este trabalho foi definido que os seios maxilares direito e esquerdo seriam avaliados nas radiografias panorâmicas digitalizadas quanto a:

(A) aspecto compatível com a normalidade;

(B) presença de espessamento da mucosa sinusal ou total opacificação do seio maxilar (velamento do seio maxilar parcial ou total);

(C) presença de cistos sinusais (fenômeno de retenção de muco);

(D) presença de comunicação buco-antral.

4.2.2 Seleção dos examinadores 
Foram selecionados aleatoriamente entre alunos e ex- alunos de pós graduação três examinadores para realização do estudo: dois radiologistas odontológicos e um clínico geral.

Com o intuito de treinar e homogeneizar os examinadores, foi entregue para cada um deles uma mídia CD-ROM contendo:

(1) instruções para execução da análise (Apêndice A),

(2) arquivo contendo as imagens a serem avaliadas e

(3) planilha para imprimir e preencher com a análise das radiografias.

Nas instruções entregues aos examinadores (1), além das instruções para a execução da análise propriamente dita, havia também um gabarito com exemplos indicativos das características radiográficas de cada um dos padrões radiográficos a serem avaliados. Os examinadores foram instruídos ainda, a não utilizar a ferramenta de aumento de tamanho das imagens.

\subsubsection{Seleção das imagens}

Para que houvesse um número mínimo representativo de cada um dos padrões radiográficos descritos anteriormente, inicialmente foi feita uma análise das tomografias computadorizadas para a escolha das radiografias da amostra. Para a análise das tomografias foi utilizado o software eFilm Workstation ${ }^{\mathrm{TM}}$ (Merge Healthcare). Esse software realiza uma reformatação das imagens das tomografias 
nos planos coronal, sagital e axial; permitindo assim, a visualização do seio maxilar em toda sua extensão e em todos os planos.

Após a análise a amostra ficou assim distribuída:

- 50 exames com aspecto compatível com a normalidade (A) em ambos os seios maxilares;

- 26 exames com presença de espessamento da mucosa sinusal ou total opacificação do seio maxilar uni ou bilateral (B);

- 15 exames com presença de cistos sinusais (fenômeno de retenção de muco) uni ou bilateral $(C)$ e

- 9 exames com presença de comunicação buco-antral uni ou bilateral (D), totalizando assim a amostra de 100 radiografias.

As radiografias foram embaralhadas aleatoriamente para que os diferentes padrões radiográficos ficassem distribuídos entre a amostra. Foi feito um gabarito denominado padrão ouro (Apêndice B) com a análise da tomografia computadorizada correspondente a cada radiografia panorâmica e seu padrão radiográfico para posterior conferência com o questionário a ser preenchido pelos examinadores. As radiografias foram então renumeradas de 1 a 100 .

Com o intuito de padronizar a análise, todas as radiografias selecionadas que estavam em formato JPEG foram então transformadas em arquivos de formato PDF, a fim de evitar que os examinadores alterassem padrões de densidade e contraste das radiografias. As radiografias foram todas armazenadas em um único arquivo de formato PDF, contendo 100 páginas, sendo que o número da página corresponde ao número da radiografia. 
4.2.4 Avaliação das imagens

Os seios maxilares direito e esquerdo foram avaliados individualmente nas radiografias panorâmicas digitalizadas quanto a:

(A) aspecto compatível com a normalidade;

(B) presença de espessamento da mucosa sinusal ou total opacificação do seio maxilar (velamento do seio maxilar parcial ou total);

(C) presença de cistos sinusais (fenômeno de retenção de muco);

(D) presença de comunicação buco-antral.

Os dados obtidos por meio da análise das radiografias panorâmicas foram comparados com o gabarito padrão ouro, baseado nos achados nas tomografias computadorizadas correspondentes. 


\section{RESULTADOS}

\subsection{Acertos Puros}

\subsubsection{Acerto completo}

Para determinarmos este índice, foi analisado individualmente para cada examinador o índice de acerto completo, ou seja, percentual de acerto para ambos os seios maxilares, simultaneamente em todas as radiografias, quando comparada a resposta de cada examinador com o padrão ouro. Considerou-se acerto completo, apenas quando as respostas dos examinadores eram exatamente iguais às do padrão ouro em ambos os seios maxilares.

Na Tabela 5.1 podemos verificar esse índice.

\begin{tabular}{l|r|r|r}
\hline & \multicolumn{3}{|c}{ Acerto Puro } \\
& Examinador 1 & Examinador 2 & Examinador 3 \\
\hline Acerto Completo & $30 \%$ & $20 \%$ & $53 \%$ \\
\hline Acerto Parcial & $50 \%$ & $27 \%$ & $35 \%$ \\
\hline Erro & $20 \%$ & $53 \%$ & $12 \%$ \\
\hline
\end{tabular}




\subsubsection{Acerto parcial}

Na Tabela 5.1 está demonstrado também o índice de acerto parcial de cada examinador.

Para determinarmos este índice, foi analisado individualmente para cada examinador o índice de acerto em apenas um dos seios maxilares (direito ou esquerdo) em todas as radiografias panorâmicas, quando comparada a resposta de cada examinador com o padrão ouro. Considerou-se acerto apenas quando as respostas dos examinadores eram iguais às do padrão ouro.

5.1.3 Coeficientes de concordância do acerto completo

Para obtenção deste coeficiente inicialmente verificamos quais as combinações de diagnóstico existentes no padrão ouro. Verificamos a existência de 13 combinações: $A A, B B, C C, A B, B A, A C, C A, B C, C B, A D, B D A, C D A$ e BDBD. Sendo:

- AA- aspecto compatível com normalidade em ambos os seios maxilares,

- BB- aspecto compatível com velamento em ambos os seios maxilares,

- CC- aspecto compatível com fenômeno de retenção de muco em ambos os seios maxilares,

- AB- aspecto compatível com normalidade no seio maxilar direito e com velamento no seio maxilar esquerdo, 
- BA- aspecto compatível com velamento no seio maxilar direito e normalidade no seio maxilar esquerdo,

- AC- aspecto compatível com normalidade no seio maxilar direito e fenômeno de retenção de muco no esquerdo,

- CA- aspecto compatível com fenômeno de retenção de muco no seio maxilar direito e normalidade no esquerdo,

- BC- aspecto compatível com velamento do seio maxilar direito e fenômeno de retenção de muco no esquerdo,

- CB- aspecto compatível com fenômeno de retenção de muco no seio maxilar direito e velamento do esquerdo,

- AD- aspecto compatível com normalidade no seio maxilar direito e presença de comunicação buco sinusal no esquerdo,

- BDA- aspecto compatível com velamento e presença de comunicação buco sinusal no seio maxilar direito e normalidade no esquerdo,

- CDA- aspecto compatível com fenômeno de retenção de muco e comunicação buco sinusal no seio maxilar direito e normalidade no esquerdo e,

- BDBD- aspecto compatível com velamento e presença de comunicação buco sinusal em ambos os seios maxilares.

Uma vez identificadas as combinações existentes, foi feita análise de concordância Kappa de cada um dos examinadores para cada uma das combinações, como demonstram as Tabelas 5.2, 5.3 e 5.4 . 
Tabela 5.2- Coeficientes de concordância do acerto completo para o examinador 1

\begin{tabular}{|c|c|c|c|c|c|c|}
\hline \multirow[b]{2}{*}{ Diagnóstico } & \multicolumn{3}{|c|}{ Examinador 1} & \multirow[b]{2}{*}{ Sensibilidade } & \multirow[b]{2}{*}{ Especificidade } & \multirow[b]{2}{*}{ Kappa } \\
\hline & $\begin{array}{c}\text { Padrão } \\
\text { Ouro }\end{array}$ & $\begin{array}{l}+ \\
\mathrm{n}\end{array}$ & - & & & \\
\hline \multirow[t]{2}{*}{ AA } & + & 12 & 38 & $24 \%$ & $96 \%$ & 0.20 \\
\hline & - & 2 & 48 & & & \\
\hline \multirow[t]{2}{*}{ BB } & + & 6 & 9 & $40 \%$ & $93 \%$ & 0.36 \\
\hline & - & 6 & 79 & & & \\
\hline \multirow[t]{2}{*}{ CC } & + & 0 & 2 & $0 \%$ & $100 \%$ & - \\
\hline & - & 0 & 98 & & & \\
\hline \multirow[t]{2}{*}{$A B$} & + & 2 & 1 & $67 \%$ & $80 \%$ & 0.13 \\
\hline & - & 18 & 79 & & & \\
\hline \multirow[t]{2}{*}{ BA } & + & 3 & 5 & $38 \%$ & $88 \%$ & 0.19 \\
\hline & - & 11 & 81 & & & \\
\hline \multirow[t]{2}{*}{ AC } & + & 1 & 4 & $20 \%$ & $98 \%$ & 0.26 \\
\hline & - & 1 & 94 & & & \\
\hline \multirow[t]{2}{*}{ CA } & + & 2 & 4 & $33 \%$ & $94 \%$ & 0.26 \\
\hline & - & 5 & 89 & & & \\
\hline \multirow[t]{2}{*}{ BC } & + & 0 & 1 & $0 \%$ & $100 \%$ & - \\
\hline & - & 0 & 99 & & & \\
\hline \multirow[t]{2}{*}{ CB } & + & 1 & 0 & $100 \%$ & $95 \%$ & 0.27 \\
\hline & - & 5 & 94 & & & \\
\hline \multirow[t]{2}{*}{$A D$} & + & 0 & 1 & $0 \%$ & $99 \%$ & -0.01 \\
\hline & - & 1 & 98 & & & \\
\hline \multirow[t]{2}{*}{ BDA } & + & 2 & 4 & $33 \%$ & $97 \%$ & 0.33 \\
\hline & - & 3 & 91 & & & \\
\hline \multirow[t]{2}{*}{ CDA } & + & 0 & 1 & $0 \%$ & $99 \%$ & -0.01 \\
\hline & - & 1 & 98 & & & \\
\hline \multirow[t]{2}{*}{ BDBD } & + & 1 & 0 & $100 \%$ & $98 \%$ & 0.49 \\
\hline & - & 2 & 97 & & & \\
\hline
\end{tabular}


Tabela 5.3- Coeficientes de concordância do acerto completo para o examinador 2

\begin{tabular}{|c|c|c|c|c|c|c|}
\hline Diagnóstico & $\begin{array}{c}\text { Padrão } \\
\text { Ouro }\end{array}$ & $\begin{array}{c}\text { Exa } \\
+ \\
n\end{array}$ & $\begin{array}{r}2 \\
- \\
\mathrm{n}\end{array}$ & Sensibilidade & Especificidade & Kappa \\
\hline \multirow[t]{2}{*}{ AA } & + & 6 & 44 & $12 \%$ & $96 \%$ & 0.08 \\
\hline & - & 2 & 48 & & & \\
\hline \multirow[t]{2}{*}{ BB } & + & 10 & 5 & $67 \%$ & $54 \%$ & 0.11 \\
\hline & - & 39 & 46 & & & \\
\hline \multirow[t]{2}{*}{ CC } & + & 0 & 2 & $0 \%$ & $92 \%$ & -0.03 \\
\hline & - & 8 & 90 & & & \\
\hline \multirow[t]{2}{*}{$A B$} & + & 0 & 3 & $0 \%$ & $95 \%$ & -0.04 \\
\hline & - & 5 & 92 & & & \\
\hline \multirow[t]{2}{*}{ BA } & + & 1 & 7 & $13 \%$ & $92 \%$ & 0.05 \\
\hline & - & 7 & 85 & & & \\
\hline \multirow[t]{2}{*}{ AC } & + & 0 & 5 & $0 \%$ & $99 \%$ & -0.02 \\
\hline & - & 1 & 94 & & & \\
\hline \multirow[t]{2}{*}{ CA } & + & 1 & 5 & $17 \%$ & $99 \%$ & 0.23 \\
\hline & - & 1 & 93 & & & \\
\hline \multirow[t]{2}{*}{ BC } & + & 0 & 1 & $0 \%$ & $96 \%$ & -0.02 \\
\hline & - & 4 & 95 & & & \\
\hline \multirow[t]{2}{*}{ CB } & + & 1 & 0 & $100 \%$ & $96 \%$ & 0.32 \\
\hline & - & 4 & 95 & & & \\
\hline \multirow[t]{2}{*}{ AD } & + & 0 & 1 & $0 \%$ & $100 \%$ & - \\
\hline & - & 0 & 99 & & & \\
\hline \multirow[t]{2}{*}{ BDA } & + & 1 & 5 & $17 \%$ & $99 \%$ & 0.23 \\
\hline & - & 1 & 93 & & & \\
\hline \multirow[t]{2}{*}{ CDA } & + & 0 & 1 & $0 \%$ & $100 \%$ & - \\
\hline & - & 0 & 99 & & & \\
\hline \multirow[t]{2}{*}{ BDBD } & + & 0 & 1 & $0 \%$ & $100 \%$ & - \\
\hline & - & 0 & 99 & & & \\
\hline
\end{tabular}


Tabela 5.4- Coeficientes de concordância do acerto completo para o examinador 3

\begin{tabular}{|c|c|c|c|c|c|c|}
\hline \multirow[b]{2}{*}{ Diagnóstico } & \multicolumn{3}{|c|}{ Examinador 3} & \multirow[b]{2}{*}{ Sensibilidade } & \multirow[b]{2}{*}{ Especificidade } & \multirow[b]{2}{*}{ Kappa } \\
\hline & $\begin{array}{c}\text { Padrão } \\
\text { Ouro }\end{array}$ & $\begin{array}{c}+ \\
\mathrm{n}\end{array}$ & $\bar{n}$ & & & \\
\hline \multirow[t]{2}{*}{ AA } & + & 35 & 15 & $70 \%$ & $74 \%$ & 0.44 \\
\hline & - & 13 & 37 & & & \\
\hline \multirow[t]{2}{*}{ BB } & + & 5 & 10 & $33 \%$ & $91 \%$ & 0.27 \\
\hline & - & 7 & 78 & & & \\
\hline \multirow[t]{2}{*}{ CC } & + & 1 & 1 & $50 \%$ & $100 \%$ & 0.66 \\
\hline & - & 0 & 98 & & & \\
\hline \multirow[t]{2}{*}{$A B$} & + & 1 & 2 & $33 \%$ & $91 \%$ & 0.13 \\
\hline & - & 8 & 89 & & & \\
\hline \multirow[t]{2}{*}{ BA } & + & 4 & 4 & $50 \%$ & $87 \%$ & 0.25 \\
\hline & - & 12 & 80 & & & \\
\hline \multirow[t]{2}{*}{ AC } & + & 1 & 4 & $20 \%$ & $100 \%$ & 0.32 \\
\hline & - & 0 & 95 & & & \\
\hline \multirow[t]{2}{*}{ CA } & + & 3 & 3 & $50 \%$ & $97 \%$ & 0.47 \\
\hline & - & 3 & 91 & & & \\
\hline \multirow[t]{2}{*}{ BC } & + & 0 & 1 & $0 \%$ & $100 \%$ & - \\
\hline & - & 0 & 99 & & & \\
\hline \multirow[t]{2}{*}{ CB } & + & 1 & 0 & $100 \%$ & $98 \%$ & 0.49 \\
\hline & - & 2 & 97 & & & \\
\hline \multirow[t]{2}{*}{ AD } & + & 0 & 1 & $0 \%$ & $100 \%$ & - \\
\hline & - & 0 & 99 & & & \\
\hline \multirow[t]{2}{*}{ BDA } & + & 2 & 4 & $33 \%$ & $99 \%$ & 0.42 \\
\hline & - & 1 & 93 & & & \\
\hline \multirow[t]{2}{*}{ CDA } & + & 0 & 1 & $0 \%$ & $100 \%$ & - \\
\hline & - & 0 & 99 & & & \\
\hline \multirow[t]{2}{*}{ BDBD } & + & 0 & 1 & $0 \%$ & $100 \%$ & - \\
\hline & - & 0 & 99 & & & \\
\hline
\end{tabular}

5.1.4 Coeficientes de concordância de acerto por padrão radiográfico

Para obtenção deste coeficiente foi analisado o acerto de cada padrão radiográfico avaliando-se os seios maxilares direito e esquerdo individualmente.

Foi considerado acerto quando o examinador marcou exatamente o mesmo diagnóstico determinado pelo padrão ouro ou ainda, os casos em que havia somente 
os padrões B ou C (velamento e fenômeno de retenção de muco, respectivamente) no padrão ouro, mas o examinador marcou também a presença de comunicação buco sinusal (D).

Nos casos em que havia presença de comunicação buco sinusal (D), foi considerado acerto quando a resposta do examinador era exatamente igual ao padrão ouro ou ainda quando o examinador marcou a presença dos padrões B e/ou C mesmo quando estes não estavam presentes.

Foi feita análise de concordância Kappa de cada um dos examinadores para cada um dos padrões radiográficos ( $A, B, C$ e D).

Os resultados seguem nas Tabelas 5.5, 5.6 e 5.7 .

Tabela 5.5- Coeficientes de concordância de acerto por padrão radiográfico para o examinador 1

\begin{tabular}{lcccccc}
\hline & Padrão & \multicolumn{2}{c}{ Examinador $\mathbf{1}$} & & & \\
Diagnóstico & Ouro & $\mathbf{n}$ & $\mathbf{n}$ & Sensibilidade & Especificidade & Kappa \\
\hline A & + & 73 & 57 & $56 \%$ & $91 \%$ & 0.41 \\
& - & 6 & 64 & & $59 \%$ & 0.26 \\
\hline B & + & 34 & 9 & $79 \%$ & $94 \%$ & 0.36 \\
& - & 64 & 93 & & & \\
\hline C & + & 7 & 10 & $41 \%$ & $85 \%$ & 0.17 \\
\hline
\end{tabular}


Tabela 5.6 Coeficientes de concordância de acerto por padrão radiográfico para o examinador 2

\begin{tabular}{|c|c|c|c|c|c|c|}
\hline \multirow[b]{2}{*}{ Diagnóstico } & \multicolumn{3}{|c|}{ Examinador 2} & \multirow[b]{2}{*}{ Sensibilidade } & \multirow[b]{2}{*}{ Especificidade } & \multirow[b]{2}{*}{ Kappa } \\
\hline & $\begin{array}{c}\text { Padrão } \\
\text { Ouro }\end{array}$ & $\begin{array}{l}+ \\
\mathrm{n}\end{array}$ & n & & & \\
\hline \multirow{2}{*}{ A } & + & 28 & 102 & $22 \%$ & $91 \%$ & 0.10 \\
\hline & - & 6 & 64 & & & \\
\hline \multirow[t]{2}{*}{ B } & + & 33 & 10 & $77 \%$ & $35 \%$ & 0.07 \\
\hline & - & 102 & 55 & & & \\
\hline \multirow[t]{2}{*}{ C } & + & 6 & 11 & $35 \%$ & $87 \%$ & 0.17 \\
\hline & - & 23 & 160 & & & \\
\hline \multirow[t]{2}{*}{ D } & + & 3 & 7 & $30 \%$ & $95 \%$ & 0.23 \\
\hline & - & 9 & 181 & & & \\
\hline
\end{tabular}

Tabela 5.7- Coeficientes de concordância de acerto por padrão radiográfico para o examinador 3

\begin{tabular}{|c|c|c|c|c|c|c|}
\hline \multirow[b]{2}{*}{ Diagnóstico } & \multicolumn{3}{|c|}{ Examinador 3} & \multirow[b]{2}{*}{ Sensibilidade } & \multirow[b]{2}{*}{ Especificidade } & \multirow[b]{2}{*}{ Kappa } \\
\hline & $\begin{array}{c}\text { Padrão } \\
\text { Ouro }\end{array}$ & $\begin{array}{l}+ \\
\mathrm{n}\end{array}$ & n & & & \\
\hline \multirow[t]{2}{*}{ A } & + & 108 & 22 & $83 \%$ & $67 \%$ & 0.50 \\
\hline & - & 23 & 47 & & & \\
\hline \multirow[t]{2}{*}{ B } & + & 26 & 17 & $60 \%$ & $80 \%$ & 0.36 \\
\hline & - & 31 & 126 & & & \\
\hline \multirow[t]{2}{*}{ C } & + & 7 & 10 & $41 \%$ & $97 \%$ & 0.44 \\
\hline & - & 5 & 178 & & & \\
\hline \multirow[t]{2}{*}{ D } & + & 2 & 8 & $20 \%$ & $98 \%$ & 0.22 \\
\hline & - & 4 & 186 & & & \\
\hline
\end{tabular}

\subsection{Acertos Agrupados}

Assumindo-se que os padrões B e C são semelhantes entre si, e que quando o examinador marcasse B no lugar de C e vice versa poderíamos considerar como acerto, obtivemos os coeficientes que seguem: 
5.2.1 Coeficiente de concordância do acerto agrupado completo

Para obtenção deste coeficiente inicialmente verificamos quais as combinações de diagnóstico eram existentes no padrão ouro. Verificamos a existência de 7 combinações: AA, GG, AG, GA, AD, GDA, GDGD. Sendo:

- AA- aspecto compatível com normalidade em ambos os seios maxilares,

- GG- aspecto compatível com velamento ou fenômeno de retenção de muco em ambos os seios maxilares

- AG- aspecto compatível com normalidade no seio maxilar direito e com velamento ou fenômeno de retenção de muco no seio maxilar esquerdo,

- GA- aspecto compatível com velamento ou fenômeno de retenção de muco no seio maxilar direito e com normalidade no esquerdo,

- AD- aspecto compatível com normalidade no seio maxilar direito e presença de comunicação buco sinusal no esquerdo,

- GDA- aspecto compatível com velamento ou fenômeno de retenção de muco e comunicação buco sinusal no seio maxilar direito e normalidade no esquerdo e,

- GDGD- aspecto compatível com velamento ou fenômeno de retenção de e presença de comunicação buco sinusal em ambos os seios maxilares.

Uma vez identificadas as combinações existentes, foi feita análise de concordância Kappa de cada um dos examinadores para cada uma das combinações, como demonstram as Tabelas 5.8, 5.9 e 5.10. 
Tabela 5.8- Coeficiente de concordância do acerto agrupado completo para o examinador 1

\begin{tabular}{|c|c|c|c|c|c|}
\hline \multirow[b]{2}{*}{ Diagnóstico } & \multicolumn{3}{|c|}{ Examinador 1} & \multirow[b]{2}{*}{ Sensibilidade } & \multirow[b]{2}{*}{ Kappa } \\
\hline & $\begin{array}{c}\text { Padrão } \\
\text { Ouro }\end{array}$ & $\begin{array}{l}+ \\
\mathbf{n}\end{array}$ & $\bar{n}$ & & \\
\hline$\overline{\mathrm{AA}}$ & $\begin{array}{l}+ \\
-\end{array}$ & $\begin{array}{c}12 \\
2\end{array}$ & $\begin{array}{l}38 \\
48\end{array}$ & $24 \%$ & 0.20 \\
\hline GG & $\begin{array}{l}+ \\
-\end{array}$ & $\begin{array}{c}11 \\
7\end{array}$ & $\begin{array}{c}8 \\
74\end{array}$ & $58 \%$ & 0.50 \\
\hline$\overline{\mathbf{A G}}$ & $\begin{array}{l}+ \\
-\end{array}$ & $\begin{array}{c}7 \\
15\end{array}$ & $\begin{array}{c}1 \\
77\end{array}$ & $88 \%$ & 0.40 \\
\hline$\overline{\mathbf{G A}}$ & $\begin{array}{l}+ \\
-\end{array}$ & $\begin{array}{c}6 \\
15\end{array}$ & $\begin{array}{c}8 \\
71\end{array}$ & $43 \%$ & 0.21 \\
\hline$\overline{\mathrm{AD}}$ & $\begin{array}{l}+ \\
-\end{array}$ & $\begin{array}{l}0 \\
1\end{array}$ & $\begin{array}{c}1 \\
98\end{array}$ & $0 \%$ & -0.01 \\
\hline$\overline{\text { GDA }}$ & $\begin{array}{l}+ \\
-\end{array}$ & $\begin{array}{l}2 \\
4\end{array}$ & $\begin{array}{c}5 \\
89\end{array}$ & $29 \%$ & 0.26 \\
\hline$\overline{\text { GDGD }}$ & $\begin{array}{l}+ \\
-\end{array}$ & $\begin{array}{l}1 \\
2\end{array}$ & $\begin{array}{c}0 \\
97\end{array}$ & $100 \%$ & 0.49 \\
\hline
\end{tabular}

Tabela 5.9- Coeficiente de concordância do acerto agrupado completo para o examinador 2

\begin{tabular}{|c|c|c|c|c|c|}
\hline \multirow{2}{*}{ Diagnóstico } & \multicolumn{3}{|c|}{ Examinador 2} & \multirow{2}{*}{ Sensibilidade } & \multirow{2}{*}{ Kappa } \\
\hline & $\begin{array}{c}\text { Padrão } \\
\text { Ouro }\end{array}$ & + & $\bar{n}$ & & \\
\hline \multirow[t]{2}{*}{ AA } & + & 6 & $\overline{44}$ & $12 \%$ & 0.08 \\
\hline & - & 2 & 48 & & \\
\hline \multirow[t]{2}{*}{ GG } & + & 17 & 2 & $89 \%$ & 0.14 \\
\hline & - & 50 & 31 & & \\
\hline \multirow[t]{2}{*}{ AG } & + & 1 & 7 & $13 \%$ & 0.08 \\
\hline & - & 5 & 87 & & \\
\hline \multirow[t]{2}{*}{$\overline{G A}$} & + & 2 & 12 & $14 \%$ & 0.06 \\
\hline & - & 8 & 78 & & \\
\hline \multirow[t]{2}{*}{$\overline{A D}$} & + & 0 & 1 & $0 \%$ & - \\
\hline & - & 0 & 99 & & \\
\hline \multirow[t]{2}{*}{$\overline{\text { GDA }}$} & + & 1 & 6 & $14 \%$ & 0.20 \\
\hline & - & 1 & 92 & & \\
\hline \multirow[t]{2}{*}{ GDGD } & + & 0 & 1 & $0 \%$ & - \\
\hline & - & 0 & 99 & & \\
\hline
\end{tabular}


Tabela 5.10- Coeficiente de concordância do acerto agrupado completo para o examinador 3

\begin{tabular}{lccccc}
\hline & \multicolumn{6}{c}{ Examinador $\mathbf{3}$} & & \\
Diagnóstico & Padrão & $\mathbf{+}$ & - & & \\
\hline Ouro & $\mathbf{n}$ & $\mathbf{n}$ & Sensibilidade & Kappa \\
\hline GG & + & 35 & 15 & $70 \%$ & 0.52 \\
& - & 13 & 37 & & 0.34 \\
\hline AG & + & 8 & 11 & $42 \%$ & 0.39 \\
& - & 8 & 73 & & 0.26 \\
\hline GA & + & 4 & 4 & $50 \%$ & - \\
& - & 6 & 86 & & 0.37 \\
\hline AD & + & 7 & 7 & $50 \%$ & - \\
& - & 15 & 71 & & $0 \%$ \\
\hline GDA & + & 0 & 1 & & \\
\hline GDGD & - & 0 & 99 & 5 & \\
& + & 2 & 92 & & \\
\hline
\end{tabular}

\subsection{Seio Maxilar Direito $=$ Seio Maxilar Esquerdo X Seio Maxilar Direito $\neq$ Seio Maxilar Esquerdo}

Para a determinação deste coeficiente, unimos em um só grupo todos os casos em que havia alteração do padrão radiográfico de normalidade em somente um dos seios maxilares. Obtivemos então grupos maiores denominados $A B^{\prime}$ e $A C^{\prime}$ (acerto puro) e AG' (acerto agrupado), que continham os padrões radiograficos $A B, B A, A C$ e $C A$ (acerto puro) e AG e GA (acerto agrupado) respectivamente. Os resultados seguem nas tabelas $5.11,5.12,5.13,5.14,5.15$ e 5.16 . 
Tabela 5.11- Seio Maxilar D = Seio Maxilar E X Seio Maxilar D\# Seio Maxilar E (acerto puro) para o examinador 1

\begin{tabular}{|c|c|c|c|c|c|}
\hline \multirow[b]{2}{*}{ Diagnóstico } & \multicolumn{3}{|c|}{ Examinador 1} & \multirow[b]{2}{*}{ Sensibilidade } & \multirow[b]{2}{*}{ Kappa } \\
\hline & $\begin{array}{c}\text { Padrão } \\
\text { Ouro }\end{array}$ & $\begin{array}{l}+ \\
\mathbf{n}\end{array}$ & $\bar{n}$ & & \\
\hline$\overline{\mathrm{AA}}$ & $\begin{array}{l}+ \\
-\end{array}$ & $\begin{array}{c}12 \\
2\end{array}$ & $\begin{array}{l}38 \\
48\end{array}$ & $24 \%$ & 0.20 \\
\hline$\overline{B B}$ & $\begin{array}{l}+ \\
-\end{array}$ & $\begin{array}{l}6 \\
6\end{array}$ & $\begin{array}{c}9 \\
79\end{array}$ & $40 \%$ & 0.36 \\
\hline$\overline{C C}$ & $\begin{array}{l}+ \\
-\end{array}$ & $\begin{array}{l}0 \\
0 \\
\end{array}$ & $\begin{array}{c}2 \\
98 \\
\end{array}$ & $0 \%$ & - \\
\hline$\overline{\mathrm{AB}^{\prime}}$ & $\begin{array}{l}+ \\
-\end{array}$ & $\begin{array}{c}5 \\
18\end{array}$ & $\begin{array}{c}6 \\
71\end{array}$ & $45 \%$ & 0.17 \\
\hline$\overline{A C^{\prime}}$ & $\begin{array}{l}+ \\
-\end{array}$ & $\begin{array}{l}3 \\
1\end{array}$ & $\begin{array}{c}8 \\
88 \\
\end{array}$ & $27 \%$ & 0.36 \\
\hline
\end{tabular}

Tabela 5.12- Seio Maxilar $D=$ Seio Maxilar $E X$ Seio Maxilar $D \neq$ Seio Maxilar E (acerto puro) para o examinador 2

\begin{tabular}{|c|c|c|c|c|c|}
\hline \multirow{2}{*}{ Diagnóstico } & \multicolumn{3}{|c|}{ Examinador 2} & \multirow{2}{*}{ Sensibilidade } & \multirow{2}{*}{ Kappa } \\
\hline & Padrão & + & $\bar{n}$ & & \\
\hline \multirow[t]{2}{*}{ AA } & + & 6 & 44 & $12 \%$ & 0.08 \\
\hline & - & 2 & 48 & & \\
\hline \multirow[t]{2}{*}{$\overline{B B}$} & + & 10 & 5 & $67 \%$ & 0.11 \\
\hline & - & 39 & 46 & & \\
\hline \multirow[t]{2}{*}{$\overline{\mathrm{CC}}$} & + & 0 & 2 & $0 \%$ & -0.03 \\
\hline & - & 8 & 90 & & \\
\hline \multirow[t]{2}{*}{$\overline{\mathrm{AB}^{\prime}}$} & + & 1 & 10 & $9 \%$ & 0.06 \\
\hline & - & 4 & 85 & & \\
\hline \multirow[t]{2}{*}{$\overline{A C^{\prime}}$} & + & 1 & 10 & $9 \%$ & 0.12 \\
\hline & - & 1 & 88 & & \\
\hline
\end{tabular}


Tabela 5.13- Seio Maxilar $D=$ Seio Maxilar E X Seio Maxilar $D \neq$ Seio Maxilar E (acerto puro) para o examinador 3

\begin{tabular}{|c|c|c|c|c|c|}
\hline \multirow{2}{*}{ Diagnóstico } & \multicolumn{3}{|c|}{ Examinador 3} & \multirow{2}{*}{ Sensibilidade } & \multirow{2}{*}{ Kappa } \\
\hline & Padrão & + & $\bar{n}$ & & \\
\hline \multirow{2}{*}{ AA } & + & 35 & 15 & $70 \%$ & 0.52 \\
\hline & - & 13 & 37 & & \\
\hline \multirow[t]{2}{*}{$\overline{B B}$} & + & 5 & 10 & $33 \%$ & 0.27 \\
\hline & - & 7 & 78 & & \\
\hline \multirow[t]{2}{*}{$\overline{C C}$} & + & 1 & 1 & $50 \%$ & 0.66 \\
\hline & - & 0 & 98 & & \\
\hline \multirow[t]{2}{*}{ AB' } & + & 5 & 6 & $45 \%$ & 0.34 \\
\hline & - & 8 & 81 & & \\
\hline \multirow[t]{2}{*}{$\overline{A C^{\prime}}$} & + & 4 & 7 & $36 \%$ & 0.50 \\
\hline & - & 0 & 89 & & \\
\hline
\end{tabular}

Tabela 5.14- Seio Maxilar D = Seio Maxilar E X Seio Maxilar D \# Seio Maxilar E (acerto agrupado) para o examinador 1

\begin{tabular}{|c|c|c|c|c|c|}
\hline \multirow[b]{2}{*}{ Diagnóstico } & \multicolumn{3}{|c|}{ Examinador 1} & \multirow[b]{2}{*}{ Sensibilidade } & \multirow[b]{2}{*}{ Kappa } \\
\hline & $\begin{array}{c}\text { Padrão } \\
\text { Ouro }\end{array}$ & $\begin{array}{l}+ \\
\mathrm{n}\end{array}$ & - & & \\
\hline$\overline{\mathrm{AA}}$ & $\begin{array}{l}+ \\
-\end{array}$ & $\begin{array}{c}12 \\
2\end{array}$ & $\begin{array}{l}38 \\
48\end{array}$ & $24 \%$ & 0.20 \\
\hline$\overline{\mathbf{G G}}$ & $\begin{array}{l}+ \\
-\end{array}$ & $\begin{array}{c}11 \\
7\end{array}$ & $\begin{array}{c}8 \\
74\end{array}$ & $58 \%$ & 0.50 \\
\hline$\overline{\text { AG' }}$ & $\begin{array}{l}+ \\
-\end{array}$ & $\begin{array}{l}13 \\
14\end{array}$ & $\begin{array}{c}9 \\
64\end{array}$ & $59 \%$ & 0.38 \\
\hline
\end{tabular}

Tabela 5.15- Seio Maxilar D = Seio Maxilar E X Seio Maxilar D\# Seio Maxilar E (acerto agrupado) para o examinador 2

\begin{tabular}{|c|c|c|c|c|c|}
\hline \multirow[b]{2}{*}{ Diagnóstico } & \multicolumn{3}{|c|}{ Examinador 2} & \multirow[b]{2}{*}{ Sensibilidade } & \multirow[b]{2}{*}{ Kappa } \\
\hline & $\begin{array}{c}\text { Padrão } \\
\text { Ouro }\end{array}$ & $\begin{array}{l}+ \\
\mathrm{n}\end{array}$ & n & & \\
\hline \multirow[t]{2}{*}{ AA } & + & 6 & 44 & $12 \%$ & 0.08 \\
\hline & - & 2 & 48 & & \\
\hline \multirow[t]{2}{*}{$\overline{\mathbf{G G}}$} & + & 17 & 2 & $89 \%$ & 0.14 \\
\hline & - & 50 & 31 & & \\
\hline \multirow[t]{2}{*}{$\overline{A G^{\prime}}$} & + & 3 & 19 & $14 \%$ & 0.11 \\
\hline & - & 4 & 74 & & \\
\hline
\end{tabular}


Tabela 5.16- Seio Maxilar D = Seio Maxilar E X Seio Maxilar D \# Seio Maxilar E (acerto agrupado) para o examinador 3

\begin{tabular}{|c|c|c|c|c|c|}
\hline \multirow[b]{2}{*}{ Diagnóstico } & \multicolumn{3}{|c|}{ Examinador 3} & \multirow[b]{2}{*}{ Sensibilidade } & \multirow[b]{2}{*}{ Kappa } \\
\hline & $\begin{array}{c}\text { Padrão } \\
\text { Ouro }\end{array}$ & $\begin{array}{l}\mathbf{n} \\
\mathbf{n}\end{array}$ & $\bar{n}$ & & \\
\hline$\overline{\mathrm{AA}}$ & + & $\begin{array}{l}35 \\
13\end{array}$ & $\begin{array}{l}15 \\
37\end{array}$ & $70 \%$ & 0.52 \\
\hline GG & $\begin{array}{l}+ \\
-\end{array}$ & $\begin{array}{l}8 \\
8\end{array}$ & $\begin{array}{l}11 \\
73\end{array}$ & $42 \%$ & 0.34 \\
\hline AG' & $\begin{array}{l}+ \\
-\end{array}$ & $\begin{array}{c}11 \\
6\end{array}$ & $\begin{array}{l}11 \\
72\end{array}$ & $50 \%$ & 0.46 \\
\hline
\end{tabular}

As respostas dos examinadores 1, 2 e 3 encontram-se no Apêncide C. 


\section{DISCUSSÃO}

$\mathrm{Na}$ literatura a radiografia panorâmica é descrita como método diagnóstico indicado para: avaliação inicial do paciente (WHITE; PHAROAH, 2004), localização de corpos estranhos (LYON, 1973), localização de dentes inclusos (BOUQUET et al., 2004) e detecção de lesões císticas no interior da cavidade do seio maxilar (LYON, 1973; OHBA, 1977; OHBA; KATAYAMA, 1976) entre outros.

A radiografia panorâmica também tem seu uso descrito na detecção de alterações patológicas dos seios maxilares, sendo sua eficácia comparada com a da técnica de Waters (OHBA, 1977; OHBA; KATAYAMA, 1976; YOSHIURA, 1993).

O desenvolvimento de técnicas de sinus lift levou a uma maior preocupação com o seio maxilar no que diz respeito a:

- prevalência de alterações patológicas nos seio maxilares previamente à realização da cirurgia de sinus lift (BEAUMONT et al., 2005);

- os efeitos dessa cirurgia sobre a fisiologia o seio maxilar (TIMMENGA et al., 2003);

- a incidência de sinusites maxilares após a realização do levantamento do assoalho do seio maxilar (TIMMENGA et al., 1997).

A Academia Americana de Radiologia Oro- Maxilo- Facial (AAOMR) publicou um artigo com os critérios de seleção de imagens para planejamento cirúrgico de colocação de implantes (TYNDAL; BROOKS, 2000). Nesse artigo, é descrita a importância de obtenção de imagens que proporcionem avaliação adequada tanto do sítio de colocação do(s) implante(s) (quantidade óssea, forma do rebordo ósseo, presença de alterações patológicas e etc.), quanto das estruturas e reparos 
anatômicos vizinhos como o canal nasopalatino, canal alveolar inferior, canal e forame mental e o seio maxilar. A Academia termina por indicar a obtenção de imagens em secção transversal (tomografias) das áreas que irão ser reabilitadas cirurgicamente com implantes.

Apesar das indicações da AAOMR, os autores Beason e Brooks (2001) e Sakakura et al. (2003) verificaram que na maioria das cirurgias para colocação de implantes realizadas, a técnica radiográfica predominantemente utilizada pelos dentistas para planejamento era a radiografia panorâmica , ao invés da tomografia preconizada pela AAOMR.

Uma vez que a radiografia panorâmica ainda é amplamente utilizada como único método de avaliação e planejamento cirúrgico para implantes e, as cirurgias de sinus lift são uma realidade freqüente no dia a dia dos implantodontistas, decidimos investigar a eficácia da radiografia panorâmica na detecção das alterações patológicas dos seios maxilares.

Ao analisarmos o índice de acerto diagnóstico dos examinadores, inicialmente consideramos somente os casos em que os examinadores acertaram o diagnóstico para ambos os seios maxilares ("acerto completo") sendo que o resultado obtido foi um índice de 30, 20 e 53\% para os examinadores 1, 2 e 3, respectivamente. Quando analisamos os casos em que ocorreu acerto no diagnóstico de apenas um dos seios maxilares ("acerto parcial"), os índices de acerto foram 50, 27 e $35 \%$ para os examinadores 1, 2 e 3, respectivamente , conforme Tabela 5.1.

Das cem radiografias analisadas, ocorreu "acerto completo" simultâneo entre os três examinadores somente em 8 exames com aspectos radiográficos assim distribuídos: 
- 4 exames tinham aspecto radiográfico compatível com a normalidade em ambos os seios maxilares,

- 2 exames com aspecto radiográfico compatível com a normalidade em um seio maxilar e velamento sinusal parcial ou total no outro seio maxilar,

- 1 exame com aspecto compatível com a normalidade em um seio maxilar e fenômeno de retenção de muco no outro e

- 1 exame com aspecto compatível com a normalidade em um seio maxilar e comunicação buco sinusal no outro seio.

Em três casos ocorreu o "erro completo" simultâneo entre os três examinadores, sendo que todos os casos apresentavam aspecto compatível com a normalidade em ambos os seios maxilares e os três examinadores marcaram que havia velamento de ambos os seios maxilares.

Estes índices vêem a confirmar que quanto mais experiência o profissional tem, maior o acerto e, portanto, melhor seu diagnóstico. Podemos fazer esta afirmação porque sabemos de antemão que o examinador 2 trata-se do clínico geral enquanto os examinadores 1 e 3 são os radiologistas odontológicos; sendo que o examinador 3 é o que tem mais anos de experiência.

Ao analisarmos as diferentes combinações diagnósticas presentes nas radiografias panorâmicas deste estudo e calcularmos o coeficiente de concordância Kappa verificamos que apenas um examinador conseguiu um índice de concordância grande (0.66), porém em apenas uma das combinações diagnósticas (Tabela 5.4). Nas demais combinações diagnósticas todos os examinadores obtiveram valores de Kappa indicativos de pequena à moderada concordância; utilizando-se a classificação proposta por Landis e Koch (1977), na qual os diferentes intervalos de valores de Kappa ficam assim classificados: <0 
concordância pobre, 0-0.2 pequena concordância, 0.21-0.40 concordância fraca, 0.41-0.60 concordância moderada, 0.61-0.80 grande concordância e 0.81-1.0 concordância praticamente perfeita.

Para determinar os valores de sensibilidade e especificidade diagnóstica para cada um dos padrões radiográficos ( $A, B, C$ e D), avaliamos os padrões individualmente nas análises de cada examinador. Entendemos por sensibilidade a capacidade do examinador em detectar o padrão radiográfico quando o mesmo está presente e, por especificidade, a capacidade do examinador de identificar a ausência do padrão radiográfico quando o mesmo não está presente.Uma vez que o examinador 2 obteve índices de acerto e coeficientes de concordância muito baixos, iremos excluí-lo das análises que seguem.

Na Tabelas 5.5 e 5.7 analisamos os padrões radiográficos individualmente para cada examinador. Quando analisamos os examinadores 1 e 3 em relação ao padrão radiográfico $A$, verificamos que apesar de o examinador 3 ter relativa alta sensibilidade para o padrão radiográfico em questão (83\%), a sua especificidade não foi tão alta (67\%). Isso ocorreu, pois apesar de detectar corretamente o padrão radiográfico $\mathrm{A}$ em $83 \%$ dos casos em que esse padrão ocorria, o examinador 3 identificou a presença deste padrão em muitos casos onde ele não estava presente (23 casos). Em contrapartida, o examinador 1 obteve uma menor sensibilidade (56\%) porém sua especificidade foi muito mais alta $(91 \%)$, uma vez que o examinador 1 diagnosticou erroneamente como padrão $\mathrm{A}$ um menor número de casos.

Ao avaliarmos o padrão radiográfico B para os mesmos examinadores, ocorre exatamente o inverso: o examinador 1 obteve elevada sensibilidade para 0 
padrão radiográfico $(79 \%)$ porém uma menor especificidade $(59 \%)$ enquanto o examinador 3 obteve menor sensibilidade (60\%) e maior especificidade (80\%).

Em relação ao padrão radiográfico $\mathrm{C}$, os examinadores obtiveram o mesmo valor de sensibilidade ,41\%, e especificidade semelhantes, 94 e $97 \%$ para os examinadores 1 e 3 respectivamente.

Em relação ao padrão radiográfico $\mathrm{D}$, o examinador 1 obteve valor moderado de sensibilidade, $50 \%$, enquanto o examinador 3 obteve apenas $20 \%$; no entanto, a especificidade do examinador 1 foi de $85 \%$ e do examinador 3 de $98 \%$.

De maneira geral, podemos dizer que quanto maior a experiência do profissional que está examinando a radiografia, maior seu acerto diagnóstico. Já no que diz respeito à especificidade diagnóstica, a experiência do profissional não interferiu na mesma.

Uma das preocupações dos implantodontistas antes da realização de uma cirurgia de sinus lift é a saúde do seio maxilar. Uma das informações que os cirurgiões deveriam obter dos exames diagnósticos é a indicação de presença ou ausência de alteração patológica no seio maxilar que irá sofrer intervenção cirúrgica. Com o objetivo de avaliar se os examinadores foram capazes de detectar alguma alteração do padrão radiográfico de normalidade $(A)$ decidimos agrupar os padrões radiográficos $\mathrm{B}$ e $\mathrm{C}$ em um só grupo denominado padrão $\mathrm{G}$ (corresponde à presença de velamento e/ou fenômeno de retenção de muco no seio maxilar). Ao avaliarmos os valores de sensibilidade e coeficiente de concordância para esse novo padrão, conseguimos identificar os exames em que os examinadores foram capazes de detectar uma alteração do padrão radiográfico $A$, porém não necessariamente acertaram especificamente a alteração patológica presente. 
Quando avaliamos o coeficiente de concordância para as combinações diagnósticas com os padrões agrupados para o examinador 1 (Tabela 5.8), verificamos que o valor de Kappa para a combinação GG é superior ao Kappa de BB e CC. Isso se dá pois em alguns casos em que o examinador marcou BB, na realidade o padrão era $\mathrm{CC}$ ou vice versa e, quando calculamos o coeficiente agrupado, consideramos como acerto essas ocorrências. Já o examinador 2 (Tabela 5.9), também apresenta um aumento do Kappa porém ainda muito pequeno, provavelmente pois este examinador detectou alterações patológicas em muitos casos em que as mesmas não ocorriam (baixa especificidade). Já quando avaliamos o examinador 3 (Tabela 5.10) verificamos que não há um aumento significativo de Kappa. Isso se deu, pois este examinador obteve maiores coeficientes Kappa quando os padrões não estavam agrupado e também pois a sua especificidade para detectar as alterações patológicas foi alta (Tabela 5.4 e 5.7).

Com o intuito de verificar se há diferença na sensibilidade diagnóstica em função de haver diferença entre os padrões radiográficos dos seios maxilares direito e esquerdo, reunimos em um mesmo grupo todos os casos em que havia padrão radiográfico de normalidade em um dos seios maxilares e padrão radiográfico de alteração patológica ( $B$ ou $C$ ) no outro seio maxilar. Obtivemos então o grupo AB' (contendo os grupos $A B$ e BA), AC' (contendo os grupos AC e CA) e AG' (contendo os grupos AG e GA). Nas Tabelas $5.11,5.12,5.13,5.14,5.1535 .16$ temos as análises dos examinadores 1,2 e 3 . Notamos não haver diferenças significativas entre os coeficientes de concordância dos casos em que ambos os seios maxilares apresentavam o mesmo padrão radiográfico (AA, BB, CC e GG) e dos casos em que os seios maxilares apresentavam padrões radiográficos diferentes ( $A B^{\prime}, A C^{\prime}$ e $A G$ '). 


\section{CONCLUSÕES}

Após análise dos resultados obtidos conclui- se que:

7.1 Apesar de menor sensibilidade, a especificidade para o diagnóstico de fenômeno de retenção de muco é maior do que para velamento total ou parcial dos seios maxilares

7.2 Não há diferença da sensibilidade diagnóstica em relação à ocorrência de alteração patológica em somente um ou em ambos os seios maxilares

7.3 A radiografia panorâmica utilizada isoladamente não oferece condições para a conclusão do diagnóstico de uma sinusite maxilar. 


\section{REFERÊNCIAS ${ }^{1}$}

Aalokken TM, Hagtvedt T, Dalen I, Kolbenstvedt A. Conventional sinus radiography compared with CT in the diagnosis of acute sinusitis. Dentomaxillofac Radiol 2003; 32:60-2.

Beason RC, Brooks SL. Preoperative implant site assessment in Southern Michigan J Dent Res [AADR abstracts] 2001;80:137.

Beaumont C, Zafiropoulos GG, Rohmann K, Tatakis, D. Prevalence of maxillary sinus disease and abnormalities in patients scheduled for sinus lift procedures. $\mathrm{J}$ Periodontol 2005;76(3):461-7.

Bouquet A, Courdet JL, Bourgeois D, Mazoyer JF, Bossard D. Contributions of reformatted computed tomography and panoramic radiography in the localization of third molars relative to the maxillary sinus. Oral Surg Oral Med Oral Pathol Oral Radiol Endod 2004;98(3):342-7.

Konen E, Faibel M, Kleinbaum Y, Wolf M, Lusky A, Hoffman C, et al. The value of Occipitomental (Water's) view in diagnosis of sinusitis: a comparative study with computed tomography. Clin Radiol 2000;55:856-60.

Landis JR, Koch CG. The measurement of observer agreement for categorical data. Biometrics 1977;33:671-79.

Lyon HE. Reliability of panoramic radiography in the diagnosis of maxillary sinus pathosis. Oral Sug Oral Med Oral Pathol 1973;35(1):124-8.

Ohba T, Katayama $\mathrm{H}$. Comparison of panoramic radiography and Water's projection in the diagnosis of maxillary sinus disease. Oral Surg Oral Med Oral Pathol 1976;42(4):534-8.

\footnotetext{
${ }^{1}$ De acordo com Estilo Vancouver. Abreviatura de periódicos segundo base de dados MEDLINE.
} 
Ohba T. Value and limitation of panoramic radiography in the diagnosis of maxillary sinus pathosis. Int J Oral Surg 1977;6(4):211-4.

Ohba T, OgawaY, ShinoharaY, HiromatsuT, Uchida A, Toyoda Y. Limitations of panoramic radiography in the detection of bony defects in the posterior wall of the maxillary sinus: an experimental study. Dentomaxillofac Radiol 1994;23(3):149-53.

Perez CA, Farman AG. Diagnostic radiology of maxillary sinus defects. Oral Surg Oral Med Oral Pathol 1988;66(4): 507-12.

Sakakura CE, Morais JAND, Loffredo LCM, Scaf G. A survey of radiographic prescription in dental implant assessment. Dentomaxillofac Radiol 2003;32(6):397400.

Timmenga NM, Raghoebar GM, Boering G, Weissenbruch R. Maxillary sinus function after sinus lift for the insertion of dental implants. J Oral Maxillofac Surg 1997;55(9):936-40.

Timmenga N, Stegenga B, Raghoebar G, Hoogstraten J, Weissenbruch R, Vissink A. The value of Water's projection for assessing maxillary sinus inflammatory disease. Oral Surg Oral Med Oral Pathol Oral Radiol Endod 2002;93(1):103-9.

Timmenga NM, Raghoebar GM, Liem RSB, Weissenbruch R, Manson WL, Vissink A. Effects of maxillary sinus floor elevation surgery on maxillary sinus physiology. Eur $\mathrm{J}$ Oral Sci 2003;111(3):189-97.

Tyndall DA, Brooks SL. Selection criteria for dental implant site imaging: A position paper of the American Academy of Oral and Maxillofacial Radiology. Oral Surg Oral Med Oral Pathol Oral Radiol Endod 2000;89(5):630-7.

White S, Pharoah M. Oral radiology. $5^{\text {a }}$ ed. St Louis: Mosby, Inc; 2004.

Yoshiura K, Ban S, Hijiya T, Yuasa K, Miwa K, Ariji E, et al. Analysis of maxillary sinusitis using computed tomography. Dentomaxillofac Radiol 1993;22(2):86-92. 
Apêndice A- Instruções para os examinadores

Prezado Examinador;

Você deverá avaliar os seios maxilares nas radiografias quanto aos seguintes aspectos:

A: Aspecto compatível com a normalidade;

B: Presença de espessamento da mucosa sinusal e/ou opacificação total do seio maxilar (velamento parcial ou total);

C: Presença de cistos sinusais (fenômeno de retenção de muco) ou

D: Presença de comunicação buco antral.

Quando da presença dos itens B, C e/ou D, deve ser anotada a presença da alteração patológica bem como a localização da mesma. Quando da definição da localização, o seio maxilar deverá ser dividido nas seguintes regiões:

- região/ parede anterior do seio- próximo ao ápice do canino superior;

- região de pré-molares- próximo ao ápice dos mesmos;

- região de molares- próximo ao ápice dos mesmos;

- região de túber e

-parede posterior do seio maxilar.

Os itens $\mathrm{B}$ e $\mathrm{D}$, bem como $\mathrm{C}$ e $\mathrm{D}$ podem estar presentes concomitantemente em um mesmo seio maxilar. Quando isso ocorrer, deve ser feita a descrição do achado.

Os seios maxilares direito e esquerdo deverão ser avaliados individualmente. Segue gabarito com exemplos de cada um dos casos descritos anteriormente. 
A: Aspecto compatível com a normalidade;

Seios maxilares apresentam-se como áreas radiolúcidas

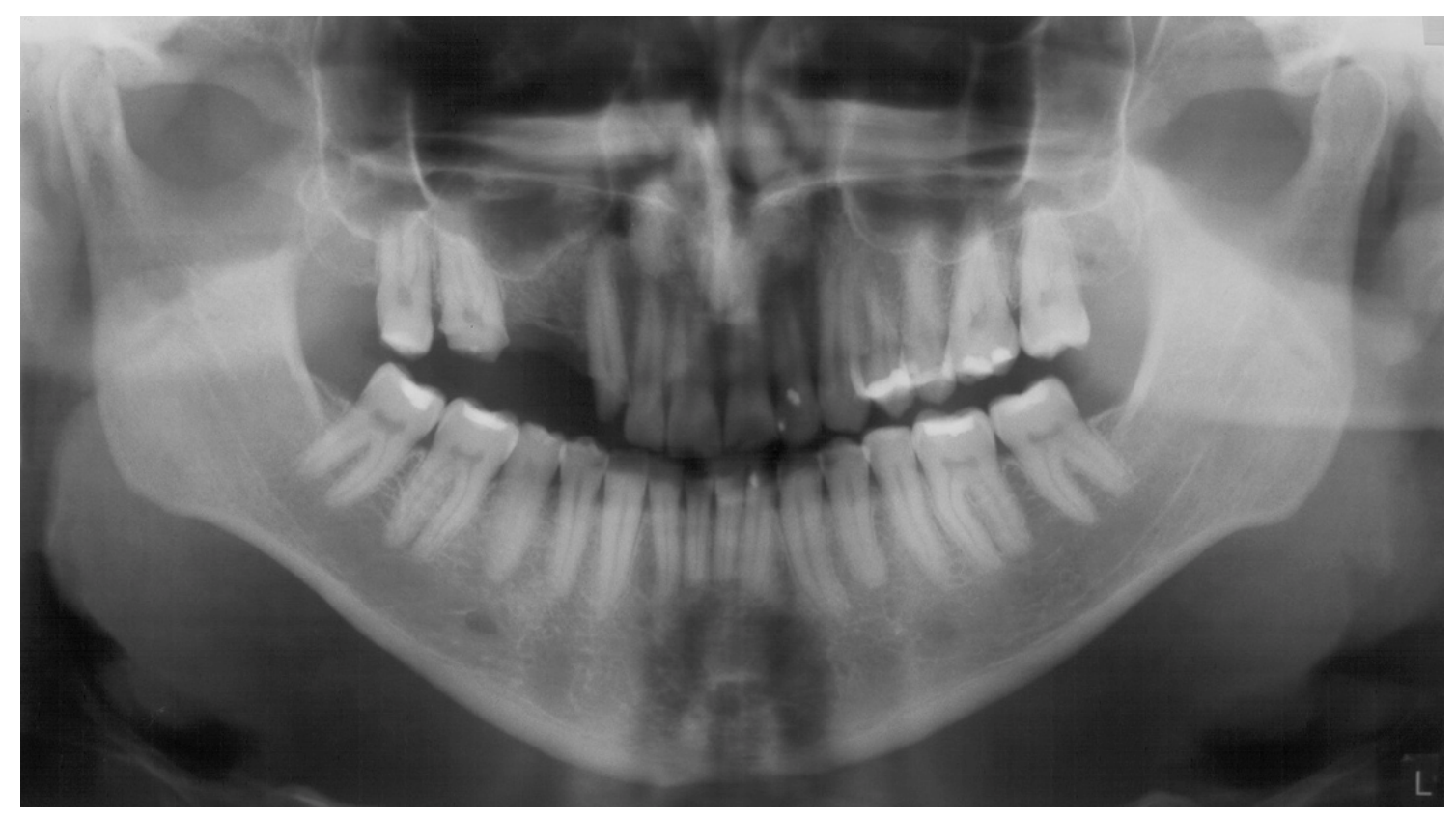

B: Presença de espessamento da mucosa sinusal e/ou opacificação total do seio maxilar (velamento parcial ou total);

Verificam-se áreas radiopacas no interior do seio maxilar, geralmente no assoalho da cavidade sinusal

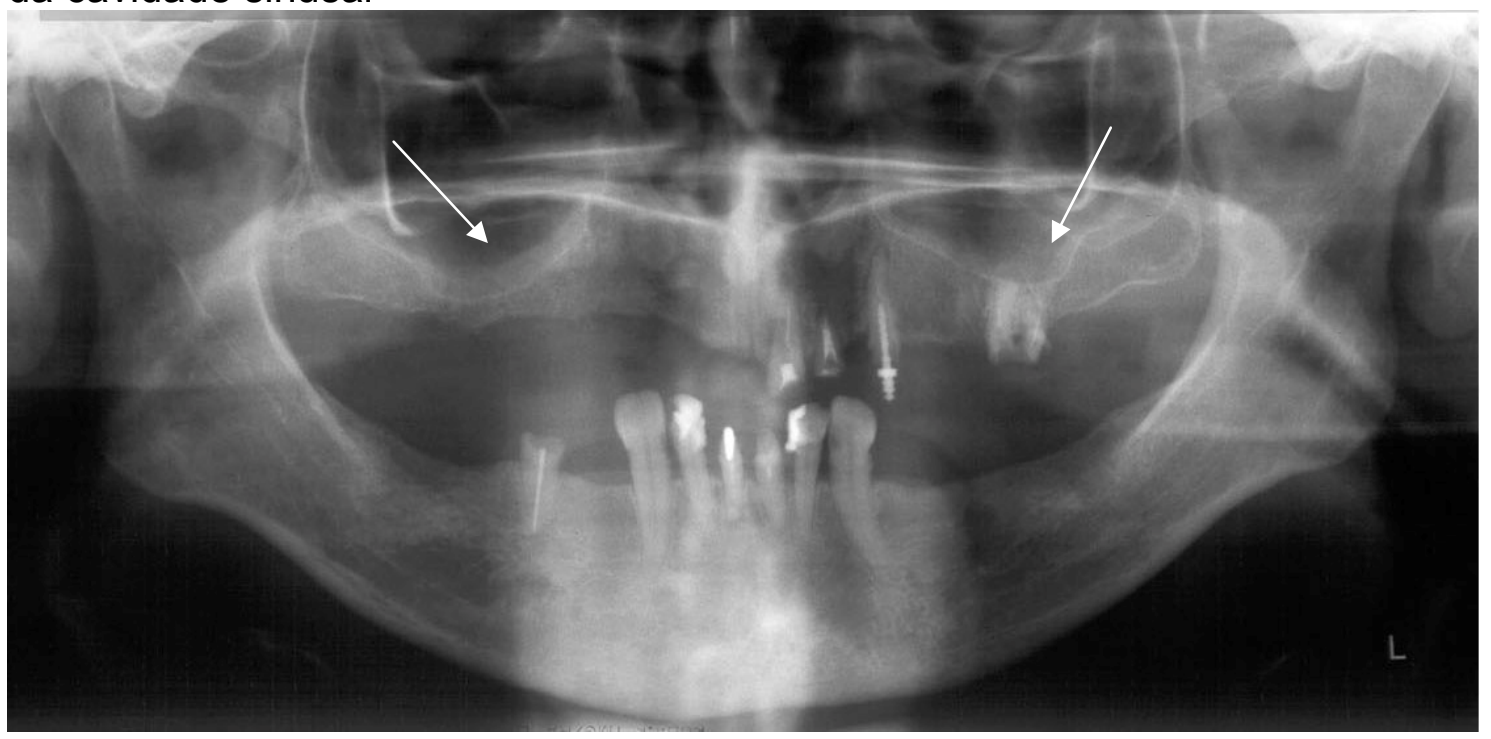


C: Presença de cistos sinusais (fenômeno de retenção de muco)

Presença de radiopacidade localizada e pediculada (de contorno bem definido)

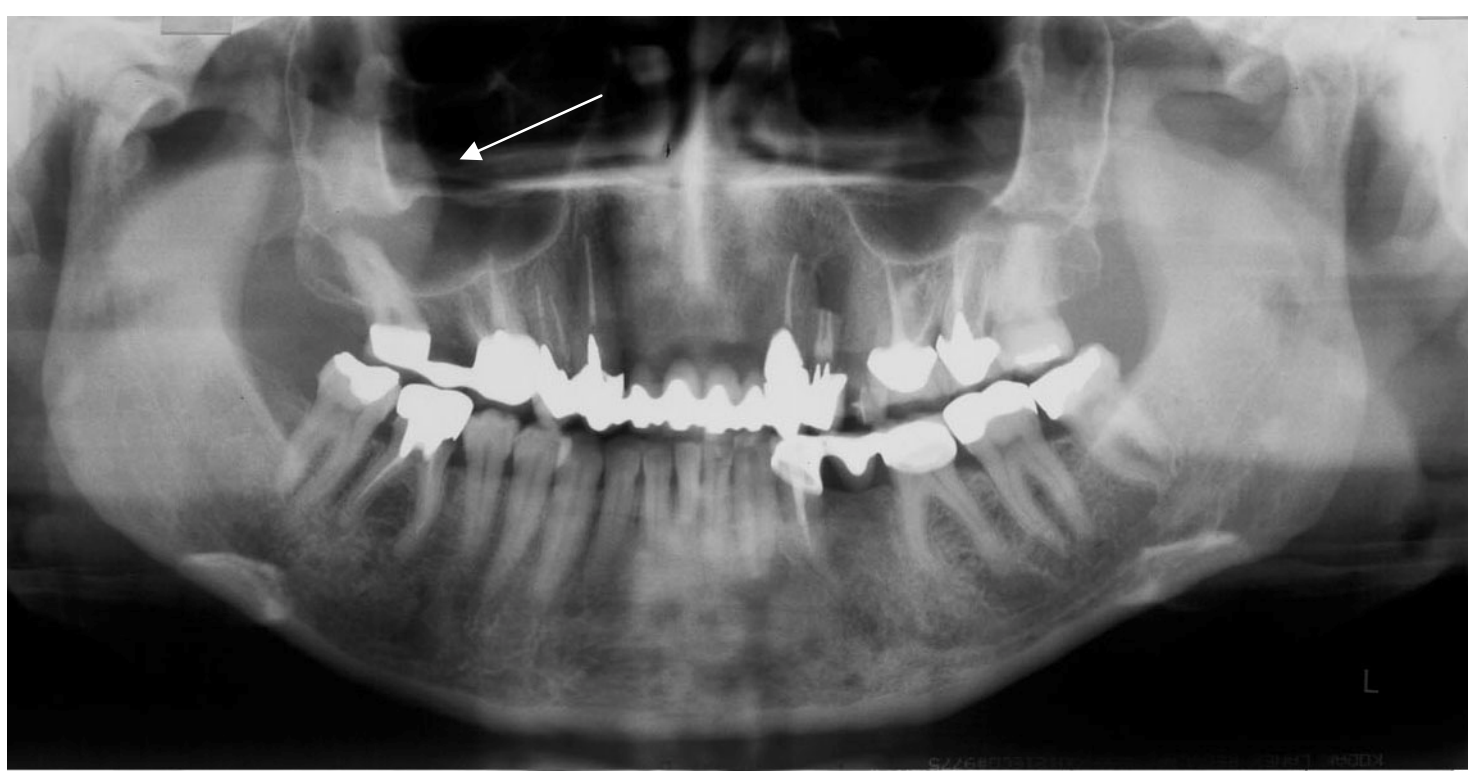

D: Presença de comunicação buco antral

Verifica-se solução de continuidade do assoalho da cavidade sinusal, ou ainda esfumaçamento do mesmo

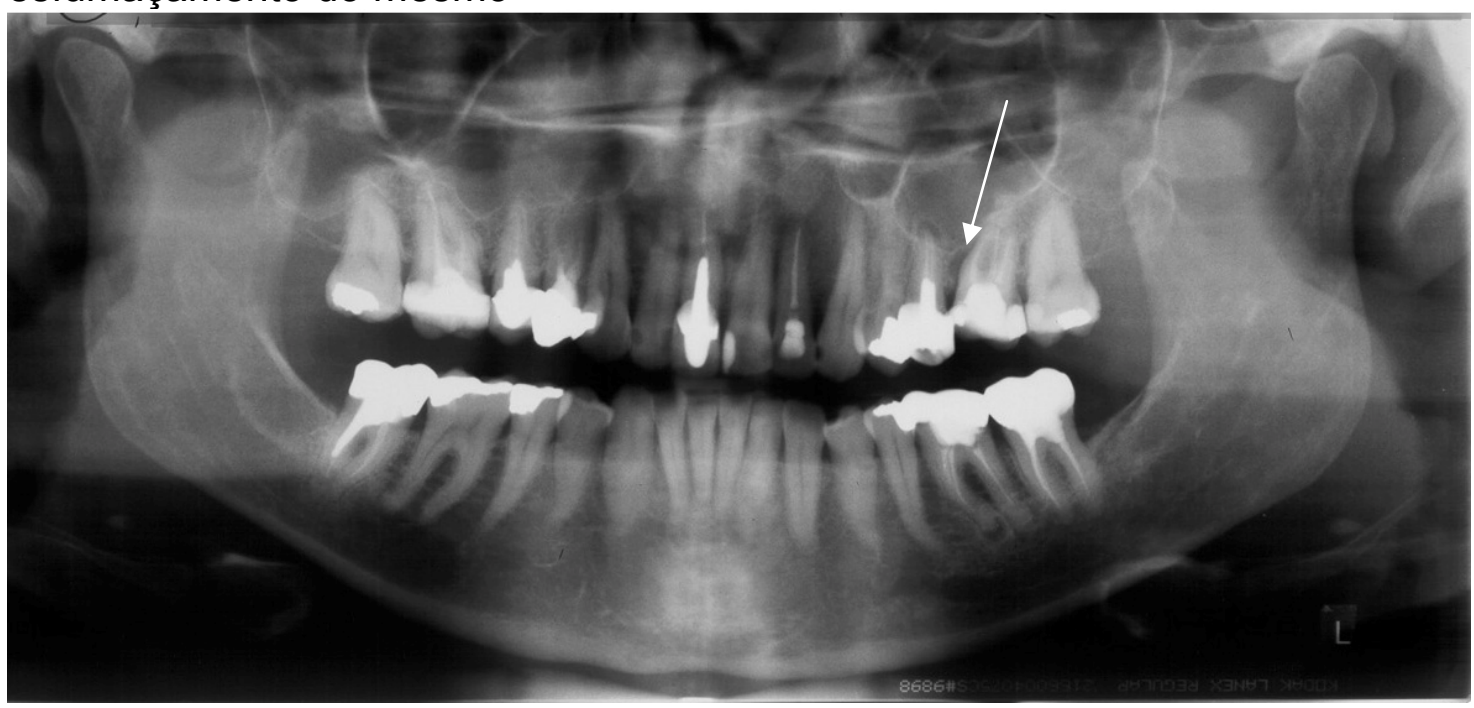

As imagens a serem avaliadas seguem em arquivo anexo intitulado "panorâmicas selecionadas". 
Apêndice B- Gabarito Padrão Ouro

\begin{tabular}{|c|c|c|}
\hline & LADO DIREITO & LADO ESQUERDC \\
\hline Panorâmica & Padrão Ouro & Padrão Ouro \\
\hline 1 & A & A \\
\hline 2 & B & $\bar{A}$ \\
\hline 3 & B & B \\
\hline 4 & BD & $\mathbf{A}$ \\
\hline 5 & $A$ & $\mathbf{A}$ \\
\hline 6 & B & A \\
\hline 7 & B & B \\
\hline 8 & $\bar{A}$ & $\bar{A}$ \\
\hline 9 & $\bar{A}$ & $\bar{A}$ \\
\hline 10 & B & B \\
\hline 11 & $\bar{A}$ & $\bar{A}$ \\
\hline 12 & C & $\bar{A}$ \\
\hline 13 & $\bar{A}$ & $\bar{A}$ \\
\hline 14 & $\bar{A}$ & $\bar{A}$ \\
\hline 15 & $\mathbf{A}$ & C \\
\hline 16 & BD & $\bar{A}$ \\
\hline 17 & $\mathbf{A}$ & $\mathbf{A}$ \\
\hline 18 & $\mathbf{A}$ & B \\
\hline 19 & $\mathbf{A}$ & $\mathbf{A}$ \\
\hline 20 & B & A \\
\hline 21 & C & B \\
\hline 22 & $\mathbf{A}$ & A \\
\hline 23 & A & A \\
\hline 24 & $A$ & $A$ \\
\hline 25 & B & B \\
\hline 26 & $\bar{A}$ & $\bar{A}$ \\
\hline 27 & B & B \\
\hline 28 & $\mathbf{A}$ & C \\
\hline 29 & A & A \\
\hline 30 & $A$ & $A$ \\
\hline 31 & A & B \\
\hline 32 & A & D \\
\hline 33 & A & A \\
\hline 34 & B & B \\
\hline 35 & B & B \\
\hline 36 & C & $\mathbf{A}$ \\
\hline 37 & $\bar{A}$ & $\bar{A}$ \\
\hline 38 & B & $\bar{A}$ \\
\hline 39 & $\bar{A}$ & $\bar{A}$ \\
\hline 40 & B & B \\
\hline 41 & C & $\mathbf{A}$ \\
\hline 42 & A & $A$ \\
\hline 43 & A & A \\
\hline 44 & B & B \\
\hline 45 & $A$ & A \\
\hline 46 & BD & A \\
\hline 47 & $A$ & A \\
\hline 48 & A & A \\
\hline 49 & BD & $\bar{A}$ \\
\hline
\end{tabular}




\begin{tabular}{|c|c|c|}
\hline 50 & C & C \\
\hline 51 & $\mathbf{A}$ & A \\
\hline 52 & $\mathbf{A}$ & A \\
\hline 53 & B & B \\
\hline 54 & $\mathbf{A}$ & A \\
\hline 55 & BD & BD \\
\hline 56 & $\mathbf{A}$ & $\mathbf{A}$ \\
\hline 57 & $\mathbf{A}$ & A \\
\hline 58 & $\mathbf{A}$ & B \\
\hline 59 & $\mathbf{A}$ & A \\
\hline 60 & C & A \\
\hline 61 & $\mathbf{A}$ & A \\
\hline 62 & B & A \\
\hline 63 & $\mathbf{A}$ & A \\
\hline 64 & $\mathbf{A}$ & A \\
\hline 65 & $\mathbf{A}$ & C \\
\hline 66 & A & A \\
\hline 67 & $\mathbf{A}$ & A \\
\hline 68 & BD & A \\
\hline 69 & C & C \\
\hline 70 & $\mathbf{A}$ & $A$ \\
\hline 71 & A & A \\
\hline 72 & A & A \\
\hline 73 & C & A \\
\hline 74 & A & A \\
\hline 75 & A & A \\
\hline 76 & B & C \\
\hline 77 & B & A \\
\hline 78 & A & A \\
\hline 79 & A & A \\
\hline 80 & B & A \\
\hline 81 & A & A \\
\hline 82 & CD & A \\
\hline 83 & A & A \\
\hline 84 & A & C \\
\hline 85 & B & B \\
\hline 86 & A & A \\
\hline 87 & B & B \\
\hline 88 & A & A \\
\hline 89 & C & A \\
\hline 90 & B & B \\
\hline 91 & $A$ & A \\
\hline 92 & B & B \\
\hline 93 & BD & A \\
\hline 94 & A & A \\
\hline 95 & B & A \\
\hline 96 & A & A \\
\hline 97 & A & A \\
\hline 98 & A & C \\
\hline 99 & $A$ & A \\
\hline 100 & B & B \\
\hline
\end{tabular}


Apêndice C- Respostas do Examinadores 1, 2 e 3

\begin{tabular}{|c|c|c|c|c|c|c|c|c|}
\hline & \multicolumn{4}{|c|}{ LADO DIREITO } & \multicolumn{4}{|c|}{ LADO ESQUERDO } \\
\hline Panorâmica & Padrão Ouro & Examinador 1 & Examinador 2 & Examinador 3 & Padrão Ouro & Examinador 1 & Examinador 2 & Examinador 3 \\
\hline 1 & $\mathbf{A}$ & $\mathrm{B}$ & $\mathrm{B}$ & $\mathrm{A}$ & A & $\mathrm{A}$ & $\mathrm{B}$ & $\mathrm{A}$ \\
\hline 2 & B & $\mathrm{BD}$ & $\mathrm{BD}$ & $\mathrm{BD}$ & A & A & A & A \\
\hline 3 & B & $\mathrm{B}$ & $\mathrm{B}$ & $\mathrm{A}$ & B & $\mathrm{B}$ & $\mathrm{B}$ & A \\
\hline 4 & BD & $\mathrm{BD}$ & $\mathrm{BD}$ & $\mathrm{BD}$ & A & A & B & A \\
\hline 5 & A & $\mathrm{C}$ & $\mathrm{C}$ & $\mathrm{C}$ & A & $\mathrm{A}$ & C & A \\
\hline 6 & B & $\mathrm{BD}$ & $\mathrm{B}$ & $\mathrm{B}$ & A & $\mathrm{BD}$ & $\mathrm{B}$ & $\mathrm{B}$ \\
\hline 7 & B & B & C & B & B & B & C & B \\
\hline 8 & A & $\mathrm{B}$ & $\mathrm{B}$ & $\mathrm{B}$ & A & A & $\mathrm{B}$ & A \\
\hline 9 & $\mathbf{A}$ & $\mathrm{B}$ & $\mathrm{B}$ & $\mathrm{B}$ & A & $\mathrm{B}$ & $\mathrm{B}$ & $\mathrm{B}$ \\
\hline 10 & B & $\mathrm{B}$ & $\mathrm{B}$ & $\mathrm{B}$ & B & $\mathrm{BD}$ & $\mathrm{B}$ & A \\
\hline 11 & $\mathbf{A}$ & B & $\mathrm{C}$ & $\mathrm{C}$ & A & $\mathrm{B}$ & C & B \\
\hline 12 & C & $B$ & $B$ & A & A & A & B & A \\
\hline 13 & A & $\mathrm{BD}$ & B & A & A & A & B & A \\
\hline 14 & A & A & B & A & A & A & A & A \\
\hline 15 & A & A & C & A & C & C & C & C \\
\hline 16 & BD & B & $B$ & $B$ & A & A & B & A \\
\hline 17 & A & A & B & A & A & A & B & A \\
\hline 18 & A & A & B & A & B & D & B & A \\
\hline 19 & A & $\mathrm{B}$ & B & A & A & B & B & A \\
\hline 20 & B & $\mathrm{BD}$ & B & B & A & A & B & A \\
\hline 21 & C & C & C & C & B & $B$ & $B$ & $B$ \\
\hline 22 & A & A & B & B & A & A & B & $B$ \\
\hline 23 & A & D & B & A & A & B & B & A \\
\hline 24 & A & $\mathrm{A}$ & A & A & A & A & B & A \\
\hline 25 & B & B & B & A & B & B & B & B \\
\hline 26 & A & A & B & A & A & $\mathrm{BD}$ & B & B \\
\hline 27 & B & A & B & A & B & A & B & A \\
\hline 28 & A & A & C & A & C & B & C & B \\
\hline 29 & A & A & B & A & A & A & B & A \\
\hline 30 & A & B & C & B & A & $\mathrm{BD}$ & $\mathrm{BD}$ & A \\
\hline 31 & A & A & B & A & B & B & B & A \\
\hline 32 & A & A & B & A & D & B & $\mathrm{BD}$ & B \\
\hline 33 & A & B & B & A & A & B & B & A \\
\hline 34 & B & B & B & B & B & B & B & A \\
\hline 35 & B & $C$ & $C$ & B & B & $B$ & B & B \\
\hline 36 & C & C & C & C & A & A & A & A \\
\hline 37 & A & $\mathrm{A}$ & $B$ & A & A & $B$ & C & A \\
\hline 38 & B & $\mathrm{BD}$ & C & B & A & B & B & A \\
\hline 39 & A & A & A & A & A & A & A & A \\
\hline 40 & B & $C$ & A & C & B & B & $C$ & A \\
\hline 41 & C & $\mathrm{C}$ & B & C & A & A & B & A \\
\hline 42 & A & $C D$ & $\mathrm{D}$ & A & A & A & B & A \\
\hline 43 & A & $\mathrm{B}$ & B & A & A & D & B & A \\
\hline 44 & B & B & B & B & B & B & B & A \\
\hline 45 & A & A & B & A & A & B & B & A \\
\hline 46 & BD & C & C & B & A & A & A & A \\
\hline 47 & A & C & B & A & A & A & A & A \\
\hline 48 & A & $\mathrm{BD}$ & $B$ & A & A & B & B & B \\
\hline 49 & BD & B & C & B & A & A & C & A \\
\hline
\end{tabular}




\begin{tabular}{|c|c|c|c|c|c|c|c|c|}
\hline 50 & C & C & B & A & C & B & C & A \\
\hline 51 & A & A & $B$ & A & A & A & $B$ & $\mathrm{~A}$ \\
\hline 52 & A & B & $B$ & A & A & A & $B$ & $\mathrm{~A}$ \\
\hline 53 & B & B & C & B & B & B & B & $B$ \\
\hline 54 & A & B & B & C & A & A & $B D$ & B \\
\hline 55 & BD & $\mathrm{BD}$ & B & B & BD & $\mathrm{BD}$ & B & B \\
\hline 56 & A & $\mathrm{A}$ & A & A & A & A & B & $\mathrm{A}$ \\
\hline 57 & A & B & B & A & A & A & A & A \\
\hline 58 & A & A & B & A & B & $B$ & A & $B$ \\
\hline 59 & A & B & B & B & A & A & B & A \\
\hline 60 & C & A & B & A & A & A & B & $\mathrm{A}$ \\
\hline 61 & A & A & B & A & A & A & A & A \\
\hline 62 & B & B & B & B & A & A & B & $\mathrm{A}$ \\
\hline 63 & A & B & B & A & A & A & B & A \\
\hline 64 & A & B & B & A & A & $B$ & A & $B$ \\
\hline 65 & A & A & C & A & C & B & C & $B$ \\
\hline 66 & A & A & B & A & A & B & C & A \\
\hline 67 & A & A & A & A & A & B & B & A \\
\hline 68 & BD & $\mathrm{BD}$ & $\mathrm{BD}$ & $\mathrm{BD}$ & A & A & A & $\mathrm{A}$ \\
\hline 69 & C & $C$ & $B$ & $C$ & C & $B$ & $B$ & $\mathrm{C}$ \\
\hline 70 & A & A & B & $B$ & A & B & B & $\mathrm{A}$ \\
\hline 71 & A & B & B & A & A & B & C & A \\
\hline 72 & A & A & B & A & A & B & B & B \\
\hline 73 & C & C & B & C & A & B & B & $\mathrm{A}$ \\
\hline 74 & A & A & B & A & A & B & B & $\mathrm{A}$ \\
\hline 75 & A & $B$ & $\mathrm{BD}$ & B & A & $D$ & B & $\mathrm{A}$ \\
\hline 76 & B & A & B & $B$ & C & B & $B C$ & $B$ \\
\hline 77 & B & $\mathrm{BD}$ & $\mathrm{BD}$ & B & A & $\mathrm{BD}$ & B & $B$ \\
\hline 78 & A & A & B & A & A & B & B & A \\
\hline 79 & A & A & B & A & A & B & B & A \\
\hline 80 & B & B & B & B & A & A & A & A \\
\hline 81 & A & $A$ & $B$ & A & A & $B$ & $B$ & $\mathrm{~A}$ \\
\hline 82 & $C D$ & C & C & C & A & D & C & $\mathrm{A}$ \\
\hline 83 & A & A & B & A & A & B & B & A \\
\hline 84 & A & A & A & A & C & B & A & A \\
\hline 85 & B & $\mathrm{BD}$ & B & $\mathrm{BD}$ & B & B & B & B \\
\hline 86 & A & A & A & A & A & A & A & $\mathrm{A}$ \\
\hline 87 & B & A & B & B & B & $C$ & A & $B$ \\
\hline 88 & A & C & A & A & A & A & A & A \\
\hline 89 & C & A & A & A & A & B & B & $\mathrm{A}$ \\
\hline 90 & B & B & B & A & B & $\mathrm{BD}$ & B & A \\
\hline 91 & A & A & A & A & A & A & A & A \\
\hline 92 & B & $\mathrm{BD}$ & $B$ & $B$ & B & $B$ & $B$ & $B$ \\
\hline 93 & BD & $\mathrm{BD}$ & $B$ & $B$ & A & $B$ & $B$ & $\mathrm{~A}$ \\
\hline 94 & A & $\mathrm{C}$ & A & A & A & A & A & $\mathrm{A}$ \\
\hline 95 & B & B & A & A & A & A & A & A \\
\hline 96 & A & A & A & A & A & A & A & $\mathrm{A}$ \\
\hline 97 & A & B & B & A & A & A & B & $\mathrm{A}$ \\
\hline 98 & A & A & A & A & C & $B$ & $B$ & $\mathrm{~A}$ \\
\hline 99 & A & $\mathrm{BD}$ & $C$ & $B$ & A & $B$ & $B$ & $B$ \\
\hline 100 & B & $\mathrm{D}$ & $B$ & $A$ & B & $B$ & $B$ & $\mathrm{~A}$ \\
\hline
\end{tabular}


Anexo A- Parecer do comitê de ética em pesquisa

\title{
UNIVERSIDADE DE SÃO PAULO \\ FACULDADE: DE ODONTOLOGIA
}

\author{
PARECER DE APROVAÇÃO \\ Protocolo 155/07
}

O grupo de trabalho indicado pelo Comitê de Ética em Pesquisa APROVOU o protocolo de pesquisa "ESTUDO COMPARATIVO DA AVALIAÇÃO DA EFICÁCIA DA RADIOGRAFIA PANORÂMICA NA DETECÇÃO DE ALTERAÇÕES PATOLÓGICAS DOS SEIOS MAXILARES EM PACIENTES QUE SERÃO SUBMETIDOS À IMPLANTES OSSEOINTEGRÁVEIS, QUANDO COMPARADA AO PADRÃO-OURO, OBTIDO PELA TOMOGRAFIA COMPUTADORIZADA HELICOIDAL", de responsabilidade da Pesquisadora RENATA ABRAMOVICZ FINKELSZTAIN, sob orientação do Professor Doutor ISRAEL CHILVARQUER.

Tendo em vista a legislação vigente, devem ser encaminhados a este Comitê relatórios anuais referentes ao andamento da pesquisa e ao término cópia do trabalho em "cd". Qualquer emenda do projeto original deve ser apresentada a este CEP para apreciação, de forma clara e sucinta, identificando a parte do protocolo a ser modificada e suas justificativas.

São Paulo, 09 de novembro de 2007

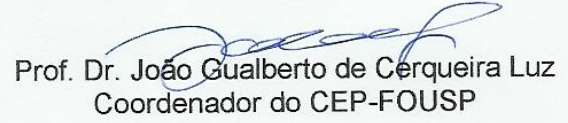

Av. Prof. Lineu Prestes, 2227 - Cidade Universitária "Armando de Salles Oliveira" CEP 05508-900 Säo Paulo - SP - Diretoria Telefax: (011) 3091- 0062/3091-7817/3091-7860 - Compras (011) 3091-7895 Impresso no S.D.0. 
Anexo B- Parecer do comitê de ética em pesquisa- adendo de alteração do título

Universidade de São Paulo

Faculdade de Odontologia

Comitê de Ética em Pesquisa

\section{DE C L A R A Ç Ã O \\ Protocolo 155/07}

Declaramos que o Comitê de Ética em Pesquisa da Faculdade de Odontologia da Universidade de São Paulo recebeu e aceitou o adendo referente a alteração do título do projeto "Estudo comparativo da avaliação da eficácia da radiografia panorâmica na detecção de alterações patológicas dos seios maxilares em pacientes que serão submetidos à implantes osseointegráveis, quando comparada ao padrão-ouro, obtido pela tomografia computadorizada Helicoidal" para "Eficácia da radiografia panorâmica na detecção de sinusites maxilares: estudo comparativo com tomografia computadorizada", de responsabilidade da Pesquisadora RENATA ABRAMOVICZ FINKELSZTAIN, sob orientação do(a) Professor(a) Doutor(a) ISRAEL CHILVARQUER.

São Paulo, 16 de junho de 2008

Prof. Dr. João Gualberto de Cerqueira Luz Coordenador do CEP-FOUSP 